\title{
The Scholarly Output of Universities and Academics in the Asia- Pacific Region Who Publish in Major Finance Journals: 2000-2007*
}

\author{
Elvis Jarnecic ${ }^{\mathrm{a}}$, Reuben Segara ${ }^{\mathrm{\dagger}}$, \\ Lydia Segarab $^{\mathrm{b}}$ and Joakim P. Westerholm ${ }^{\mathrm{a}}$
}

\begin{abstract}
The study examines the scholarly output of all universities and their finance academics in the Asia-Pacific region. We evaluate the scholarly output of 1,341 research academic staff across 300 leading Asia-Pacific universities in the period 2000 to 2007. A significant contribution of our study is that it presents ranking league tables for finance journals with respect to journal quality. The necessity of well defined ranking tables help university executive management, government policy and funding bodies in better assessing research performance. The study also constructs a new measure called to Research Productivity Dependency (RPD) index, which acts as a risk management mechanism to aid universities better assess their reliance on key individual research productive academics.
\end{abstract}

\section{JEL Classification: G00; Z00}

Keywords: Rankings; Research; Finance; Asia-Pacific Universities

\footnotetext{
${ }^{a}$ Finance Discipline, Faculty of Economics and Business, The University of Sydney, Sydney, N.S.W. 2006, Australia

${ }^{\mathrm{b}}$ School of Accounting, College of Business, University of Western Sydney, Penrith, N.S.W. 1797, Australia

${ }^{\dagger}$ Corresponding author. Mail: Room 447, H69 - Economics and Business Building, University of Sydney, N.S.W 2006, Australia. E-mail: R.Segara@econ.usyd.edu.au (Reuben Segara)

* We acknowledge the helpful comments from Alex Frino, Robert Faff, and David Gallagher among others. These comments have considerably improved this paper. We are responsible for any remaining errors.
}

\section{Introduction}

In this study, we undertake an assessment of the scholarly output of universities and other institutions in the Asia-Pacific region and their key research active staff members who specialise in the field of finance. These assessments are important because they help university administrators, academics and prospective students to gauge the relative standing of universities and their associated academics across the Asia-Pacific region. Perhaps, it is not surprising then that there has been plenty of research undertaken periodically to assess the ranking of various universities, disciplines and their associated academics throughout various regions around the world. This is consistent with a plethora of research that periodically ranks specific disciplines within an institution, solely based upon its research output. Some examples include Niemi (1987), Alexander and Mabry (1994), Borokhovich, Bricker and Simkins (1995), Chan, Chen and Steiner (2001, 2004), and Chan, Chen, and Lung (2005) in finance; Weber and Stevenson (1981), Brown and Gardner (1985), Brown (1996), and Chan, Chen and Cheng (2007) in accounting; Niemi (1988), Bakir, Vitell and Rose (2000), and Cheng, Chan and Chan (2003) in marketing; and Scott and Mitias (1996), Jin and Yau (1999), and Collins, Cox and Stango (2000) in economics, among others. The majority of these studies have examined the research performance of various disciplines in the North American region, albeit a few in other geographical locations. 
The Australasian Accounting Business \& Finance Journal, September, 2008. Jarnecic, Segara, Segara, and Westerholm: Scholarly Output Academics Asia-Pacific Finance.

Vol. 2, No.3. Page 27.

There are several motivations for this study. First, the research performance of universities in the Asia-Pacific region has become an increasingly topical issue to university administrators. This is most evident by a recent keynote address by the Deputy Vice Chancellor of Monash University, who states that "Universities are increasingly becoming self-conscious of the need to be 'international', relevant and research driven to maintain or improve their position in the rankings." (see Fahey, 2007). Collaboration amongst universities to form new and sustainable partnerships is one of the avenues suggested to achieve this goal. This trend has begun, where in an Australian first, the University of Sydney and Australian National University announced a collaboration in research, teaching and recruitment to boost their presence in both the international and domestic market (The Australian, 'Accord a magnet for star recruits,' January 23, 2005, p.33). By enhancing a disciplines scholarly output record, universities can improve their status and can compete more effectively for research funding, attract and keep the best graduate students and academics (see Moore and Taylor, 1980), and seek and retain the well regarded Association to Advance Collegiate Schools of Business International (AACSB) accreditation (see Udell, Parker and Pettijohn, 1995). ${ }^{1}$

Second, the progress of the top Asia-Pacific institutions provided in our study, allows policy makers to gauge the effectiveness of research assessment practices implemented by countries in the Asia-Pacific region used to encourage scholarly output. This information is particularly important, considering that there have been a number of changes to research assessment practices for higher education in these countries since 1999 (see von Tunzelmann and Mbula, 2003). These policy changes have led to a shift from quantitative to qualitative assessment and increased the importance of academic publications in the assessment of research and its ultimate funding. Since changes in 1999 to the Research Assessment Exercises (RAE) in Hong Kong, panel members involved in these exercises have reported real and substantial improvements in research activities of Hong Kong's institutions, both in terms of quality and quantity (see French, Massy and Young, 2001).

In Australia, the government announced on 21 December 2007 that it would assess the performance of the higher education industry by way of a new Research Quality Framework (RQF) to be run during 2009. According to press releases, the RQF replacement will be an internationally-recognised, metrics based research quality assurance system, which will be rigorous, transparent, equitable, and will incorporate international peer review. In light of this recent development to the RQF in Australia, our study provides current information on research productivity progress based on quality, which can assist government policy makers to create an effective and comprehensive design for a new RQF (or equivalent) in Australia.

Third, the provision of academic ranking league tables helps key research active staff members to assess their research productivity relative to their peers across the Asia-Pacific region. Consequently, those key academic staff who are more research active improve their chance of securing tenure and promotion, negotiating successfully for market loading and salary

\footnotetext{
${ }^{1}$ Universities in Australia and New Zealand are allocated funds from the Department of Education and Training (DEST) and Tertiary Education Commission (TEC), respectively. These government agencies typically assign heavy weight to research productivity (see Williams and Van Dyke, 2004) in their decision process. The AACSB International is the premier accrediting agency for bachelor, master and doctoral degree programs in business administration and accounting. Earning accreditation will confirm the Faculty's ongoing commitment to quality, continuous improvement and excellence in business education, as well as further raise the international profile of the Faculty.
} 
The Australasian Accounting Business \& Finance Journal, September, 2008. Jarnecic, Segara, Segara, and Westerholm: Scholarly Output Academics Asia-Pacific Finance.

Vol. 2, No.3. Page 28.

supplementation, and increasing their professional profile (see Pierce and Garven, 1995). Those academic staff who are not listed on the academic league tables can only be encouraged to improve their research productivity. This encouragement is emphasised by the recent announcement by Curtin University of Technology (based in Western Australia) to make about 150 'non research-active' lecturers redundant during the next three years and replace them with 'research active' lecturers as part of the vice chancellor's bid to reposition Curtin as a top research university (The Australian, 'Curtin to cut 150 lecturers,' January 23, 2005, p.35).

Finally, by providing the most updated ranking tables of universities across the Asia-Pacific region, academic institutions can use any improvement in their ranking to signal the quality of their faculty to prospective full fee paying domestic and foreign students. This signalling tool is especially important to those universities who desire and want to maintain their major contributor status to world higher education. Of the OECD countries in the Asia-Pacific region, Australia ranks best at fifth place in absolute terms from the intake of foreign students in tertiary education behind only that of the United States, United Kingdom, and France for both 2000 and 2005. [see 2007 Organisation for Economic Cooperation and Development (OECD) Education at a glance report, Table C3.8 (web only)]. ${ }^{2}$ Notably, New Zealand and Korea have improved in attracting a larger base of international students.

This study recognises that Chan et. al., (2005) recently examined the research productivity of the finance profession across the Asia-Pacific region for the period 1990 to 2004. Nonetheless, it is noted that our study extends the work of Chan et. al. (2005) in three important ways. First, our study provides a more thorough investigation of assessing the scholarly output of universities and academics across four finance journal groups, each of which act as a surrogate measure of varying perceived journal quality. Our primary ranking measure uses a fractional score approach to adjust for the quantity of articles, termed the weighted article count. In contrast, Chan et. al. (2005) construct a JF-equivalent page count as their primary ranking measure, which they claim adjusts for both quantity and quality. They contend that this is a better measurement based on the argument that shorter papers have less influence than full articles and apply this to their entire set of 21 finance journals examined. ${ }^{4}$

We believe that our approach to assess scholarly output is superior, as the reader can observe the ranking of universities and academics and any changes to those ranks between the four finance journal groups used. Second, a measure to gauge the dependency of a university on individual research-producing staff is created. This measure, which we term the Research Productivity Dependency (RPD) index, is a useful tool to assess an institution's risk assessment of its reliance on key individual research productive academics. Third, this study re-examines trends in scholarly output of institutions and individual finance academics in the Asia-Pacific region, for a broader set of finance journals that reflect the regionality in publishing. There is evidence to show that academics prefer to publish in local and/or regional journals (see Brinn, Jones and Pendlebury, 2001). For this reason, the inclusion of finance journals in our journal list, such as

2 Based on the 2004 OECD Education at a glance report, we note that New Zealand was ranked 19th out of 27 OECD countries for the intake of tertiary students in 2002.

3 From 2001 to 2005, New Zealand improved its market share (rank) of worldwide foreign tertiary students from 0.45 percent (rank 21) to 2.55 percent (rank 8). Over the same period, Korea slightly improved its market share (rank) of worldwide foreign tertiary students from 0.18 percent (rank 26) to 0.57 percent (rank 21).

4 It is noteworthy to mention that Chan, Chen and Cheng (2007) adopt a weighted article count in their global rank of accounting programmes, instead of their preferred measure that adjusts for both quantity and quality. 
The Australasian Accounting Business \& Finance Journal, September, 2008. Jarnecic, Segara, Segara, and Westerholm: Scholarly Output Academics Asia-Pacific Finance.

Vol. 2, No.3. Page 29.

Accounting \& Finance and the Australian Journal of Management cannot afford to be excluded when assessing the scholarly output of Asia-Pacific institutions and their academics. Additionally, this study uses the more recent period 2000 to 2007 in assessing scholarly output. Over this period, countries in the Asia-Pacific region have invested considerable resources in their higher educational sectors with the objective of social and economic advancement (Woodhall, 1999) and have made a number of changes to their research assessment practices (see von Tunzelmann and Mbula, 2003). We believe that updated rankings are increasingly important to measure the 'health' of universities and their academic staff, as higher education faces a period of limited revenue streams and rising expenses.

This study performs five tasks. First, we ranked institutions and authors in the Asia-Pacific region, in terms of their scholarly output in finance publications. These rankings are based upon published data collected from 24 finance journals (see Section 2). Second, we compared the top Asia-Pacific institutions to those in North America to ascertain their equivalent standing. Third, we analysed the research productivity progress of the top Asia-Pacific institutions for various sub-periods in our sample period to determine the extent of their rank variation. Fourth, we listed and ranked in terms of scholarly output, the most published academic research staff in the region over the sample period. Lastly, we identified the extent of dependency that each leading university in the Asia-Pacific region have on their published academics. All these tasks are performed for four finance journal groups. The remainder of this paper is structured as follows. Section 2 describes the data and method used to rank the institutions and their faculty members contained in our sample of published articles. Section 3 reports the results of our analysis and Section 4 presents the concluding remarks.

\section{Data and method}

We construct a Finance Ranking System (FinRank) database for the period 2000 to 2007. The FinRank database contains a list of publications in finance journals from the year 2000 to date, and classifies institutions and their academics according to their geographic regions -AsiaPacific, Europe and the Americas. The FinRank database has been manually compiled from electronic copies of 24 major finance journals. ${ }^{5}$ The authors' names, their institutions and the total pages of the article were extracted from these electronic copies. The 24 major finance journals included in this database are: Journal of Finance, Review of Financial Studies, Journal of Financial Economics, Journal of Financial and Quantitative Analysis, Journal of Business, Journal of Corporate Finance, Journal of Financial Markets, Financial Analysts Journal, Financial Management, Journal of Financial Intermediation, Journal of Financial Research, Journal of Financial Services Research, Journal of Empirical Finance, Financial Review, Review of Quantitative Finance and Accounting, European Financial Management, Journal of Banking and Finance, Journal of Portfolio Management, Journal of Futures Markets, Journal of International Money and Finance, Pacific Basin Finance Journal, Journal of Business Finance and Accounting, Australian Journal of Management and Accounting and Finance.

\footnotetext{
${ }^{5}$ All manually collected data was proof read for accuracy. Some authors use slightly different names in different published articles, such as $\mathrm{CH}$ Chan, $\mathrm{C}$ Chan, and Chung Chan. If this was suspected, additional research was undertaken to verify the "true name" of the author, at which point one name would be used to standardise our database for all publications for that author. Similarly cross checking and verification was undertaken for institutions that may have changed names across the sample period of our study.
} 
The selection of the 24 scholarly journals chosen is based on their quality and influence on financial research. Our choice and reasoning for this selection include the following:

a) The journals needed to meet minimum longevity requirements, in order to assess the research productivity of the finance profession in the Asia-Pacific region. Consequently, the journals chosen must have been published for at least the eight year period of our study from 2000 to 2007. We note that all of the journals chosen have been around for at least the past fifteen years, except for the Journal of Business, which ceased publication with the November 2006 issue. $^{6}$ The Journal of Business is still included in our database because it is regarded as one of the top five finance journals (see Chen and Huang, 2007).

b) Chan, et. al. (2005) use a set of 21 journals that are similar to ours, in order to assess the research productivity of the finance profession in the Asia-Pacific region for the fifteen year period from 1990 to 2004. The three new journals that we decide to include are Accounting and Finance, Australian Journal of Management and European Financial Management. The inclusion of these three finance journals is based upon their high reputation in their respective regions (see Maberly and Pierce, 2007). Additionally, all three journals have been accepted for indexing in the Web of Science Social Sciences citation Index (SSCI), the world's foremost citation index published by Thomson Scientific in the USA. This shows that all these journals are internationally recognised, and together with their associated regional popularity, are worthy to be included in the finance journals examined in our study.

c) Many of the journals chosen are regarded to be among the most prominent financial journals listed by Oltheten, Theoharakis and Travlos (2005). Their study defines a list of 66 finance journals and other media publications based on journal quality perceptions and readership patterns. Of the 24 journals in our study, 21 are the same as those ranked by Oltheten, et. al. (2005).

It is noteworthy to mention one limitation of this study, which is also identified and present in Chan, et. al. (2005). This limitation occurs when articles are co-authored in the set of journals examined, by one or more academic staff from a different discipline to finance, such as those in accounting, statistics and/or economics. Because many of the author associations by discipline are not specified in the articles, the ranking performed in this study may overstate the rankings of specific finance departments. Despite this limitation, we agree with the remarks by Chan et. al. (2005) that publications of finance articles from other academic staff members in different disciplines to finance only serve to enhance the finance program in that same institution.

\subsection{Computing weighted and unweighted articles for ranking procedure}

To compute the number of weighted articles by institution and/or academic researcher, we adopt a fractional score approach suggested in the ranking literature (see Lindsey, 1980) to make adjustments to the publication data. If there were $N$ authors for an article, each author would receive $1 / N$ credit for the published article. Similarly, adjustment was also made for the institutional affiliation of the author. If an author had $M$ affiliations, the contribution of the article

\footnotetext{
${ }^{6}$ In recognition of the increased specialisation in business scholarship, as reflected in the emergence of many specialised business journals, the Journal of Business decided to cease publication of its more broadly focused journal, after nearly eight decades of publication by the University of Chicago Press.
} 
among each of that authors associated institutions would be $1 /(M \times N)$ credit. For example, if a paper has two authors (A1 and A2) with the first author (A1) belonging to three institutions (X, Y and $\mathrm{Z}$ ) and the second author (A2) belonging to two institutions (C and D), then 0.167 credit in weighted articles would each be allocated to institutions $\mathrm{X}, \mathrm{Y}$ and $\mathrm{Z}$ and 0.25 credit in weighted articles would each be allocated to institutions $C$ and D. Individual authors in this hypothetical article would receive 0.50 credit in weighted articles. The weighted articles for the period analysed, for each institution and/or author were then cumulated for ranking purposes. Unweighted articles were found by cumulating the number of publications each institution or author produced during the period examined.

\subsection{Computing total weighted JF-equivalent pages for ranking procedure}

A JF-equivalent page count that was constructed by Chan et. al. $(2001,2005)$ is computed in this study. Total page counts for each article are converted to Journal of Finance (JF) equivalent pages, which enables each article to be comparable with one another. To find the JF-equivalent pages, 3 full text typical pages (without equations, footnotes or graphs) are randomly selected from each of the 24 journals and the number of words per page was counted. The average number of words per page was calculated, and this was taken as the number of words on a typical page of the journal concerned. This number was then divided by the corresponding number of words on a typical JF page to come up with the relevant adjustment factor. For example, if there are 517 words on a typical page of the Journal of Financial Economics and 544 words in the Journal of Finance, the total word count of the Journal of Financial Economics was converted to JFequivalent pages by the adjustment factor 0.9504 (i.e., 517 divided by 544). To find the weighted JF-equivalent pages for any articles printed in the Journal of Financial Economics, the number of weighted pages for each author and/or each institution associated with this journal would be multiplied by this adjustment factor. Once the weighted JF-equivalent pages were calculated for each particular author and institution, their respective values were summed to find their total score or total weighted JF-equivalent pages.

The JF-equivalent page count measure is claimed by Chan et. al. $(2001,2005)$ to adjust for both quantity and quality. We contend that the JF-equivalent page count allows articles to be comparable in terms of word length, but this in no way reflects quality or any meaningful measure of research productivity for a number of reasons. To claim an author with 20 standardised pages in, say, Accounting and Finance is more productive than an author with 15 standardised pages in, say, the Journal of Financial Economics, seems to be without merit. Aside from perceptions of quality or impact, differences in editorial policy also contribute to differences in the style and length of expositions. To compare papers on such a basis is likely to be flawed even when a comparison is made within a single journal. For example, a paper that can rely on efficient mathematical notation to report a major advancement in theory is likely to be much shorter, than, say, an international comparative study that considers market and participant differences and is discursive with respect to the historical development of institutional differences. The differences may be even exacerbated because equations are excluded from the construction of the JF-equivalent page count measure.

\subsection{Computing the Research Productivity Dependency Index}

For each of the top 10 Asia-Pacific institutions based upon 24 finance journals, we analyse the extent of their dependency on individual academic staff who published in all finance journals examined. For each institution, a four step procedure is employed to compute this measure. First, 
all academic staff from the same institution who published an article over a specific two-year period is summed, giving a total number of published staff for each period in our sample.

Second, we count the number of weighted articles for each of these staff members in that period. Third, the number of weighted articles for each staff member is divided by the total number of published staff for the same period. A series of values is then obtained, where we refer to each value as the 'Relative Individual Research Productivity' (RIRP) index. In effect, the RIRP index identifies any 'star' performers relative to other research active academics in that same institution. Fourth, the coefficient of variation of the RIRP series for each institution is then calculated, which we name the Research Productivity Dependency (RPD) index. The RPD index indicates how dependent the institution is on individual research active academic staff. A low(high) RPD index means that there is less(more) dependency on a few research orientated staff members in the same institution to publish in the 24 finance journals examined.

During 2000 to 2007, all 24 journals contain 7,911 articles written by 7,572 authors from 1,735 institutions with 8,659.12 weighted articles, or 189,441.18 JF-equivalent pages. Of the 7,572 authors and 1,735 institutions, 1,341 authors and 300 institutions were from the Asia-Pacific region. Their 1,341 authors published a total of 1,218.78 weighted articles, or 25,270.84 JFequivalent pages. This indicated that in terms of weighted pages (JF-equivalent pages), AsiaPacific institutions produced 14.08 percent ( 13.33 percent) of all the published pages in these 24 scholarly finance journals during the eight year period.

Our study uses the total number of weighted articles for each particular author and/or institution as the primary measure of scholarly output. ${ }^{7}$ We also report the ranks based on weighted JFequivalent pages only for references, as prior studies use these measures [e.g., Chan, et. al. (2001, 2004, 2005)]. Though we recognise that some people might view that the Social Science Citation Index (SSCI) impact factor is a sensible metric to rank scholarly output, it suffers from some major drawbacks. A significant problem of using the SSCI impact factor is that it can be biased by citations outside the finance field and is often biased in favour of specialised topics within the corporate finance area [see Borokhovich, Bricker and Simkins (2000)]. Even if we chose to use the SSCI impact factor to rank journals, it is not available for most finance journals in all years. Additionally, we note that another method of quality assessment has been the use of citation counts, which are available on Web of Science, Scopus and Google Scholar. However, critics claim that citation counting has serious problems or limitations that impact its validity, especially in the social science and humanities fields (see MacRoberts and MacRoberts, 1989, 1996; Reed, 1995; Seglen, 1998; Wallin, 2005; and Neuhaus, Neuhaus, Asher and Wrede, 2006). This paper does not intend to investigate citation analysis and other possible alternatives to panel-based assessment. Instead, the ranking of these institutions and authors are carried out across four different groups of finance journals, which act as a surrogate measure of varying journal quality perceptions. These four groups include:

1. All 24 finance journals used in our study;

2. The top 10 finance journals in our list as reported by Oltheten et. al. (2005) [hereafter referred to as Group 1]. These top 10 journals include: Journal of Finance, Journal of Financial

\footnotetext{
It is noted that our performance measurement doe not adjust for the size of production units; that is, the number of potential publishers in finance studies in each university. This has the potential to underestimate the research productivity of small universities. However, we share the same belief of Chan, et. al. (2004) that university reputation is affected by total academic power more so than the size of its production units.
} 
The Australasian Accounting Business \& Finance Journal, September, 2008. Jarnecic, Segara, Segara, and Westerholm: Scholarly Output Academics Asia-Pacific Finance.

Vol. 2, No.3. Page 33.

Economics, Review of Financial Studies, Journal of Financial and Quantitative Analysis, Journal of Business, Journal of Banking and Finance, Financial Management, Financial Analysts Journal, Journal of Corporate Finance, and the Journal of Financial Intermediation; and

3. The top 10 finance journals in our list as reported by Chen and Huang (2007) [hereafter referred to as Group 2]. These authors use an Author Affiliation Index (AAI) approach to finance journal rankings. ${ }^{8}$ The top 10 journals in their list include: Journal of Finance, Review of Financial Studies, Journal of Financial Economics, Journal of Financial and Quantitative Analysis, Journal of Business, Journal of Corporate Finance, Journal of Financial Markets, Financial Analysts Journal, Financial Management, and the Journal of Financial Intermediation;

4. The top 5 finance journals. These include: Journal of Finance, Journal of Financial Economics, Review of Financial Studies, Journal of Financial and Quantitative Analysis, and the Journal of Business. These journals are generally perceived to be the top 5 finance journals by finance academics worldwide (see Oltheten et. al., 2005) ${ }^{9}$

We believe our ranking procedure used is superior to prior studies, primarily because it allows the reader to assess university and academic rankings based on their perceptions of quality within those groups.

\section{Results from ranking the finance profession in the Asia-Pacific region}

\subsection{General rankings of institutions in 24 finance journals}

Table 1 reports the ranking of the top 20 Asia-Pacific institutions over 2000 to 2007 by the total number of weighted articles in the 24 finance journals examined. ${ }^{10}$ In addition to the ranking of individual institutions, Table 1 also reports their respective country of origin, total number of weighted, unweighted articles and JF-equivalent pages and the ranking of these top 20 institutions by JF-equivalent pages.

The University of New South Wales (UNSW) received the top rank with a total weighted article count of 88.92. This university has been the most research active in finance publications across Australia for not only the period 1990 to 2004 (see Chan, et. al. 2005, Table 2, p.588), but has maintained its number one position in the Asia-Pacific region for the period 2000 to 2007. This result shows that finance academics from the UNSW have on average produced more publications in the 24 scholarly finance journals examined, relative to other universities across the Asia-Pacific region. It is recognised that this result maybe attributed to the larger academic staff ratio that the UNSW has relative to other universities in the region, which helps contribute to their higher total number of weighted articles. Nonetheless, the top ranking of the UNSW indicates that it has a strong emphasis on recruiting active research staff and/or engendering a

${ }^{8}$ The AAI is defined as the ratio of articles authors by faculty at the world's top 80 finance programs to the total number of articles by all authors.

9 It should be noted that the difference in relative rankings between the top 5- journals and top-4 journals (excludes the Journal of Business) are marginal. For example, a rank correlation between the weighted article count in the top 4 journals and in the top-5 journals for the top-20 Asia-pacific institutions (authors) is $99.74 \%$ $(95.59 \%)$. Subsequently, we do not report the ranking tables for the top 4 journals in our study.

10 For the interested reader, Appendix 1 reports the remaining ranking of the top 50 Asia-Pacific universities for the eight year period 2000 to 2007 based upon 24 finance journals (Panel A); the top 10 finance journals in group 1 (Panel B) and group 2 (Panel C); and the top 5 finance journals (PanelD). 
The Australasian Accounting Business \& Finance Journal, September, 2008. Jarnecic, Segara, Segara, and Westerholm: Scholarly Output Academics Asia-Pacific Finance.

Vol. 2, No.3. Page 34.

research driven orientated culture that has been based on incentives of tenure, promotion and/or market loading. Whatever the case, the model that the UNSW has adopted is effectively working and may prove to be a benchmark, which should be followed by other universities in the AsiaPacific region. That said, it is important not to be complacent with such results. Ideally, consistency in a university ranking should be maintained across the different groups of finance journals examined (see Tables 2 to 4 ).

Table 1

Ranking of the top 20 Asia-Pacific institutions by total weighted articles in 24 major finance journals

\begin{tabular}{|c|c|c|c|c|c|c|}
\hline Rank & Institution name & Countrv & $\begin{array}{l}\text { Weighted } \\
\text { articles }\end{array}$ & $\begin{array}{l}\text { Unweighted } \\
\text { articles }\end{array}$ & $\begin{array}{l}\text { Weighted } \\
\text { JF-Pages }\end{array}$ & $\begin{array}{c}\text { Rank based on } \\
\text { Weighted JF-Pages }\end{array}$ \\
\hline 1 & University of New South Wales (Go8) & Australia & 88.92 & 183 & 1818.61 & 1 \\
\hline 2 & Hong Kong University of Science and Technology & Hong Kong & 60.50 & 117 & 1483.86 & 2 \\
\hline 3 & University of Sydney (Go8) & Australia & 54.92 & 125 & 1044.45 & 4 \\
\hline 4 & Hong Kong Polytechnic University & Hong Kong & 49.58 & 113 & 1126.86 & 3 \\
\hline 5 & Monash University (Go8) & Australia & 47.08 & 108 & 913.86 & 6 \\
\hline 6 & University of Melbourne (Go8) & Australia & 44.25 & 82 & 838.30 & 9 \\
\hline 7 & University of Queensland (Go8) & Australia & 40.83 & 93 & 796.32 & 10 \\
\hline 8 & National University of Singapore & Singapore & 40.67 & 84 & 919.75 & 5 \\
\hline 9 & Nanyang Technological University & Singapore & 40.17 & 97 & 895.72 & 7 \\
\hline 10 & Chinese University of Hong Kong & Hong Kong & 39.92 & 92 & 879.22 & 8 \\
\hline 11 & City University of Hong Kong & Hong Kong & 30.08 & 71 & 646.32 & 11 \\
\hline 12 & University of Western Australia (Go8) & Australia & 25.75 & 63 & 547.96 & 13 \\
\hline 13 & University of Auckland & New Zealand & 24.83 & 58 & 552.22 & 12 \\
\hline 14 & Australian National University (Go8) & Australia & 24.08 & 49 & 440.50 & 15 \\
\hline 15 & Royal Melbourne Institute of Technology & Australia & 23.50 & 54 & 434.81 & 16 \\
\hline 16 & National Taiwan University & Taiwan & 21.42 & 53 & 462.15 & 14 \\
\hline 17 & University of Hong Kong & Hong Kong & 18.17 & 39 & 361.51 & 20 \\
\hline 18 & Victoria University of Wellington & New Zealand & 18.00 & 29 & 363.87 & 19 \\
\hline 19 & Massey University & New Zealand & 17.92 & 45 & 364.04 & 18 \\
\hline 20 & University of Technology, Sydney & Australia & 17.67 & 37 & 373.41 & 17 \\
\hline
\end{tabular}

Notes:

This table provides a ranking of Asia-Pacific institutions ranked by total weighted articles in 24 major finance journals from 2000 to 2007 . The weights are by co-authorship and co-affiliation. The number of unweighted articles and the country where the institution is geographically located are also provided. The rank number of these top 20 institutions by weighted JF-equivalent pages is also reported.

The remaining top five institutions are: Hong Kong University of Science and Technology $(60.50$ articles), University of Sydney (54.92 articles), Hong Kong Polytechnic University (49.58 articles), and Monash University (47.08 articles). The research output across all Asia-Pacific universities in the 24 finance journals analysed is highly skewed. For example, the top 5, top 10 and the top 20 institutions generate approximately 25 percent, 42 percent and 60 percent of all weighted articles, respectively. Examining Table 1, we find that 60 percent of the top 5 institutions in the Asia-Pacific region are from Australia. It is noteworthy to mention that only three of the universities in the top 5 (i.e., UNSW, Hong Kong University of Science and Technology (HKUST) and Hong Kong Polytechnic University) have maintained their current standing in scholarly output from 1990 to 2004 (see Chan, et. al. 2005, Table 2, p.588). From Table 1, we observe that 9 out of the top 20 institutions are from Australia, and 3 from New Zealand compared with 5 from Hong Kong.

This suggests that a voluminous amount of research papers are produced by academics in the Oceanic region (i.e., Australia and New Zealand) compared to other countries in Asia. It is also noted that 7 out of the 9 Australian universities from the top 20 institutions, are members of the 
Group of Eight (Go8) universities. ${ }^{11}$ This result indicates that a majority of the long-established Australian universities are leading the rankings in scholarly output in the area of finance. This result is not surprising, as the Go8 universities have been reported to receive over 70 percent of national competitive research grants and conduct over 60 percent of all Australian university research. ${ }^{12}$ However, to our surprise, we observe that the long established universities in the AsiaPacific region, such as National Taiwan University (rank 16), University of Hong Kong (rank 17), National Seoul University (rank 59) and the University of Tokyo (rank 60) rank behind the newer institutions such as the HKUST (rank 2) and Hong Kong Polytechnic University (rank 4). Clearly, this shows that the long established 'traditional' institutions in Asia cannot automatically be assumed to be research active in finance publications, at least in our sample period.

\subsection{General rankings of institutions using the top 10 and top 5 finance journals}

From Tables 2 to 4, we report the individual rank of the top 20 institutions in the Asia-Pacific region over 2000 to 2007 by total number of weighted articles based upon the top 10 and top 5 finance journals (as defined in Section 2). The name of the university, country in which the university is located, total number of weighted, unweighted articles and weighted JF-equivalent pages and the ranking of these universities by their JF-equivalent pages are also shown.

Table 2

Ranking of the top 20 Asia-Pacific institutions by total weighted articles based upon the top 10 finance journals (Group1)

\begin{tabular}{|c|c|c|c|c|c|c|}
\hline Rank & Institution name & Countrv & $\begin{array}{l}\text { Weighted } \\
\text { articles }\end{array}$ & $\begin{array}{l}\text { Unweighted } \\
\text { articles }\end{array}$ & $\begin{array}{l}\text { Weighted } \\
\text { JF - Pages }\end{array}$ & $\begin{array}{c}\text { Rank based on } \\
\text { Weighted JF-Pages }\end{array}$ \\
\hline 1 & Hong Kong University of Science and Technology & Hong Kong & 37.50 & 75 & 997.06 & 1 \\
\hline 2 & University of New South Wales (Go8) & Australia & 20.83 & 41 & 481.71 & 2 \\
\hline 3 & National University of Singapore & Singapore & 17.33 & 35 & 414.58 & 4 \\
\hline 4 & Chinese University of Hong Kong & Hong Kong & 16.08 & 38 & 426.71 & 3 \\
\hline 5 & Hong Kong Polytechnic University & Hong Kong & 14.58 & 32 & 381.90 & 5 \\
\hline 6 & City University of Hong Kong & Hong Kong & 11.75 & 25 & 301.21 & 6 \\
\hline 7 & Nanyang Technological University & Singapore & 10.67 & 28 & 273.47 & 7 \\
\hline 8 & Singapore Management University & Singapore & 9.08 & 22 & 189.25 & 11 \\
\hline 9 & Korea University & Korea & 8.75 & 19 & 238.50 & 8 \\
\hline 10 & University of Hong Kong & Hong Kong & 7.92 & 18 & 195.46 & 9 \\
\hline 11 & University of Melbourne (Go8) & Australia & 7.50 & 12 & 189.50 & 10 \\
\hline 12 & University of Sydney (Go8) & Australia & 5.92 & 12 & 126.87 & 12 \\
\hline 13 & Monash University (Go8) & Australia & 4.92 & 13 & 106.00 & 14 \\
\hline 14 & Kyoto University & Japan & 4.50 & 5 & 94.12 & 17 \\
\hline 14 & Victoria University of Wellington & New Zealand & 4.50 & 7 & 120.84 & 13 \\
\hline 16 & National Taiwan University & Taiwan & 4.08 & 9 & 97.10 & 16 \\
\hline 17 & Massey University & New Zealand & 4.00 & 10 & 89.79 & 18 \\
\hline 18 & University of Queensland (Go8) & Australia & 3.83 & 10 & 80.68 & 20 \\
\hline 19 & Australian National University & Australia & 3.58 & 10 & 103.15 & 15 \\
\hline 19 & National Chung Cheng University & Taiwan & 3.58 & 9 & 83.58 & 19 \\
\hline
\end{tabular}

Notes:

This table provides a ranking of Asia-Pacific institutions ranked by total weighted articles based upon the top 10 finance journals (Group 1) from 2000 to 2007 . The weights are by co-authorship and co-affiliation. The number of unweighted and weighted article count and the country where the institution is geographically located are also provided. The rank number of these top 20 institutions by weighted JF-equivalent pages is also reported.

${ }^{11}$ The Group of Eight (Go8) universities has been operating as an informal network of vice-chancellors since 1994. It was fully incorporated in September 1999 to ensure that Australia continues to have universities of world-class standard. The The Group of Eight represents Australia's leading universities. Membership of the group consists of the vice-chancellors (presidents) of: The University of Adelaide, The Australian National University, The University of Melbourne, Monash University, The University of New South Wales, The University of Queensland, The University of Sydney and The University of Western Australia.

12 Please refer to the following website for more information about facts and figures of the Group of Eight universities in Australia:http://www.go8.edu.au/about/facts.htm 
The Australasian Accounting Business \& Finance Journal, September, 2008. Jarnecic, Segara, Segara, and Westerholm: Scholarly Output Academics Asia-Pacific Finance.

Vol. 2, No.3. Page 36.

Table 3

Ranking of the top 20 Asia-Pacific institutions by total weighted articles based upon the top 10 finance journals (Group 2)

\begin{tabular}{|c|c|c|c|c|c|c|}
\hline Rank & Institution name & Countrv & $\begin{array}{l}\text { Weighted } \\
\text { articles }\end{array}$ & $\begin{array}{l}\text { Unweighted } \\
\text { articles }\end{array}$ & $\begin{array}{l}\text { Weighted } \\
\text { JF - Pages }\end{array}$ & $\begin{array}{c}\text { Rank based on } \\
\text { Weighted JF-Pages }\end{array}$ \\
\hline 1 & Hong Kong University of Science and Technology & Hong Kong & 35.00 & 72 & 954.27 & 1 \\
\hline 2 & National University of Singapore & Singapore & 12.00 & 26 & 299.50 & 2 \\
\hline 3 & Chinese University of Hong Kong & Hong Kong & 9.75 & 25 & 267.02 & 3 \\
\hline 4 & Korea University & Korea & 9.75 & 22 & 262.12 & 4 \\
\hline 5 & Hong Kong Polytechnic University & Hong Kong & 8.92 & 20 & 228.26 & 5 \\
\hline 6 & University of New South Wales (Go8) & Australia & 8.67 & 20 & 215.84 & 7 \\
\hline 7 & City University of Hong Kong & Hong Kong & 7.92 & 19 & 225.29 & 6 \\
\hline 8 & University of Hong Kong & Hong Kong & 6.92 & 15 & 172.68 & 8 \\
\hline 9 & Singapore Management University & Singapore & 6.83 & 15 & 138.68 & 10 \\
\hline 10 & University of Melbourne (Go8) & Australia & 5.50 & 9 & 147.18 & 9 \\
\hline 11 & Nanyang Technological University & Singapore & 4.42 & 11 & 134.94 & 11 \\
\hline 12 & National Taiwan University & Taiwan & 4.08 & 9 & 97.10 & 12 \\
\hline 13 & University of Sydney (Go8) & Australia & 3.50 & 5 & 81.92 & 14 \\
\hline 13 & Victoria University of Wellington & New Zealand & 3.50 & 5 & 94.79 & 13 \\
\hline 15 & University of Auckland & New Zealand & 3.33 & 7 & 70.59 & 15 \\
\hline 16 & Kyoto University & Japan & 3.00 & 3 & 60.48 & 18 \\
\hline 17 & Kobe University & Japan & 2.83 & 4 & 64.77 & 17 \\
\hline 18 & Australian National University (Go8) & Australia & 2.25 & 6 & 69.33 & 16 \\
\hline 19 & Monash University (Go8) & Australia & 2.17 & 5 & 32.76 & 34 \\
\hline 19 & National Central University, Taiwan & Taiwan & 2.17 & 4 & 57.23 & 20 \\
\hline
\end{tabular}

Notes:

This table provides a ranking of Asia-Pacific institutions ranked by total weighted articles based upon the top 10 finance journals (Group 2 ) from 2000 to 2007. The weights are by co-authorship and co-affiliation. The number of unweighted and weighted article count and the country where the institution is geographically located are also provided. The rank number of these top 20 institutions by weighted JF-equivalent pages is also reported.

Table 4

Ranking of the top 20 Asia-Pacific institutions by total weighted articles based upon the top 5 finance journals

\begin{tabular}{|c|c|c|c|c|c|c|}
\hline Rank & Institution name & Country & $\begin{array}{c}\text { Weighted } \\
\text { articles }\end{array}$ & $\begin{array}{l}\text { Unweighted } \\
\text { articles }\end{array}$ & $\begin{array}{l}\text { Weighted } \\
\text { JF - Pages }\end{array}$ & $\begin{array}{c}\text { Rank based on } \\
\text { Weighted JF-Pages }\end{array}$ \\
\hline 1 & Hong Kong University of Science and Technology & Hong Kong & 26.83 & 57 & 717.37 & 1 \\
\hline 2 & National University of Singapore & Singapore & 8.50 & 18 & 215.12 & 2 \\
\hline 3 & Korea University & Korea & 7.42 & 17 & 189.38 & 4 \\
\hline 4 & Chinese University of Hong Kong & Hong Kong & 7.17 & 19 & 191.35 & 3 \\
\hline 5 & University of Melbourne (Go8) & Australia & 5.17 & 8 & 139.55 & 5 \\
\hline 6 & Singapore Management University & Singapore & 5.00 & 12 & 108.68 & 8 \\
\hline 7 & University of Hong Kong & Hong Kong & 4.92 & 11 & 120.50 & 7 \\
\hline 8 & Hong Kong Polytechnic University & Hong Kong & 4.83 & 10 & 137.75 & 6 \\
\hline 9 & Victoria University of Wellington & New Zealand & 3.50 & 5 & 94.79 & 11 \\
\hline 10 & University of New South Wales (Go8) & Australia & 3.42 & 10 & 102.25 & 9 \\
\hline 11 & Nanyang Technological University & Singapore & 3.33 & 8 & 102.05 & 10 \\
\hline 12 & City University of Hong Kong & Hong Kong & 3.08 & 8 & 86.68 & 12 \\
\hline 13 & National Taiwan University & Taiwan & 2.42 & 5 & 50.12 & 15 \\
\hline 14 & University of Auckland & New Zealand & 2.33 & 5 & 56.01 & 13 \\
\hline 15 & National Central University, Taiwan & Taiwan & 1.83 & 3 & 49.60 & 16 \\
\hline 16 & Seoul National University & Korea & 1.67 & 5 & 52.87 & 14 \\
\hline 17 & Australian National University (Go8) & Australia & 1.58 & 4 & 46.03 & 17 \\
\hline 18 & Monash University (Go8) & Australia & 1.50 & 3 & 25.94 & 28 \\
\hline 18 & Royal Melbourne Institute of Technology & Australia & 1.50 & 3 & 33.36 & 20 \\
\hline 18 & University of Queensland (Go8) & Australia & 1.50 & 4 & 36.91 & 19 \\
\hline
\end{tabular}

Notes:

This table provides a ranking of Asia-Pacific institutions ranked by total weighted articles based upon the top 5 finance journals from 2000 to 2007. The weights are by co-authorship and co-affiliation. The number of unweighted and weighted article count and the country where the institution is geographically located are also provided. The rank number of these top 20 institutions by weighted JF-equivalent pages is also reported. 
The Hong Kong University of Science and Technology (HKUST) has consistently maintained its' number one position based upon the top 10 and top 5 finance journals over the period 2000 to 2007. This is consistent with their ranking from 1990 to 1999 based upon 21 finance journals used in the Chan, et. al. (2001) study. For the HKUST, their number 1 rank in the Asia-Pacific region has also been recognised by the academic journal Financial Management in 2002. The number 1 rank of HKUST is not surprising, as this university has focused its recruiting drives to maintain their world class faculty, in order to achieve consistent recognition for their finance research endeavours. ${ }^{13}$ This is consistent with the idea that the ever increasing selectivity in research funding based upon RAEs has led universities to enter the 'transfer market' to acquire and facilitate the work of 'star' researchers to maximise 'outputs' through reduced teaching and administrative commitments (see Nolan, 2005). Success in achieving such outcomes by HKUST is observed in Table 4, where this university produced 3.12 times more weighted articles than the next best ranked university (i.e., National University of Singapore). It is observed that the ranks for Asia-Pacific universities experience changes from Tables 1 to 4. Notably, Korea University progresses from rank 23 based upon 24 finance journals to rank 3 based upon the top 5 finance journals. Improvements in ranks are also experienced by three universities in Hong Kong, two universities in Singapore, and one university from each of the countries of Australia, New Zealand and Taiwan. ${ }^{14}$ This observation highlights that a ranking procedure using a single set of finance journals can lead to misleading results. For example, in Chan, et. al. (2005), Korea University is ranked 23 after they claim to adjust for the quantity and quality of articles published across 21 finance journals examined. The league tables presented in our study provides greater insight to the reader in the evaluation of university rankings.

Comparing university rankings based upon the top 10 finance journals (see Table 3 ) and the top 5 finance journals (see Table 4) to those in Table 1, reveals that there are no Australian universities in the top 5 list. The three universities that dropped off the top 5 list (from Tables 3 and 4) are the UNSW, University of Sydney and Monash University. Nonetheless, these three Australian universities still remain on the top 25 list. It can be argued that the higher proportion of Australian universities in the top 5 list as reported in Table 1 are attributable to: (1) the inclusion of Australian-based journals; (2) them being focused towards quantity of publications over quality; (3) perceptions that there is a barrier of entry and a familiarity bias to getting published in a top tier US journal relative to those outside the top 10. This conjecture is consistent with Brinn, Jones and Pendlebury (2001), who find that European based academics prefer to publish in local and/or regional journals; and/or (4) a natural tendency for researchers who specialise in a specific area of finance to publish in specialist journals, which fall outside the top 10. For example, academics who specialise in a particular area of finance such as futures markets or portfolio management will not have their published work included in the scholarly output measure because the Journal of Futures Markets and Journal of Portfolio Management does not fall within the top finance journal list.

\footnotetext{
${ }^{13}$ World class faculty are defined by HKUST as those academic scholars who hold PhDs from internationallyacclaimed universities. These universities as defined by HKUST include: British Columbia, Chicago, Columbia Cornell, Harvard, Illinois, Indiana, Michigan, MIT, New York University, Ohio State, Princeton, Purdue, Rochester, Southern California, Stanford, Texas, UC Berkeley, UCLA, Virginia, Washington, Wharton and Yale.

${ }^{14}$ The universities include: HKUST, Chinese University of Hong Kong, University of Hong Kong, National University of Singapore, Singapore Management University, University of Melbourne, Victoria University of Wellington and National Taiwan University.
} 
The Australasian Accounting Business \& Finance Journal, September, 2008. Jarnecic, Segara, Segara, and Westerholm: Scholarly Output Academics Asia-Pacific Finance.

Vol. 2, No.3. Page 38.

\subsection{Comparison with the North American institutions}

Table 5 compares the top 10 Asia-Pacific institutions with those in the United States and Canada during 2000 to 2007 by total weighted article count using all 24 finance journals (Panel A) and the top 10 finance journals in Group 1 (Panel B) and Group 2 (Panel C); and the top 5 finance journals (Panel D). Institutions in both the United States and Canada are ranked using the same methodology used to rank the Asia-Pacific institutions as described earlier.

Table 5

A comparison of the top 10 leading Asia-Pacific universities with North American universities during 2000 to 2007 by total weighted article count.

\begin{tabular}{|c|c|c|c|c|c|}
\hline \multicolumn{3}{|c|}{ Asia-Pacific } & \multicolumn{3}{|c|}{ United States and Canada } \\
\hline Rank & Institution name & $\begin{array}{l}\text { Weighted } \\
\text { articles }\end{array}$ & Rank & Institution name & $\begin{array}{l}\text { Weighted } \\
\text { articles }\end{array}$ \\
\hline \multicolumn{6}{|c|}{ Panel A. Comparison of the top 10 Asia-Pacific universities with North American universities by total weighted article count in 24 finance journals } \\
\hline 1 & University of New South Wales (Go8) & 88.92 & $5 / 6$ & Harvard University/University of Pennsylvania & $92.20 / 85.87$ \\
\hline 2 & Hong Kong University of Science and Technology & 60.50 & $10 / 11$ & University of Illinois/Duke University & $64.67 / 59.92$ \\
\hline 3 & University of Sydney (Go8) & 54.92 & $14 / 15$ & Stanford University/University of Wisconsin & $55.33 / 53.33$ \\
\hline 4 & Hong Kong Polytechnic University & 49.58 & $19 / 20$ & Cornell University/Massachusetts Institute of Technology (MIT) & $51.42 / 48.08$ \\
\hline 5 & Monash University (Go8) & 47.08 & $23 / 24$ & University of North Carolina/University of Toronto & $47.17 / 45.67$ \\
\hline 6 & University of Melbourne (Go8) & 44.25 & $28 / 29$ & University of Notre Dame/The Ohio State University & $44.50 / 42.58$ \\
\hline 7 & University of Queensland (Go8) & 40.83 & $29 / 30$ & The Ohio State University/Emory University & $42.58 / 39.50$ \\
\hline 8 & National University of Singapore & 40.67 & $29 / 30$ & The Ohio State University/Emory University & $42.58 / 39.50$ \\
\hline 9 & Nanyang Technological University & 40.17 & $29 / 30$ & The Ohio State University/Emory University & $42.58 / 39.50$ \\
\hline 10 & Chinese University of Hong Kong & 39.92 & $29 / 30$ & The Ohio State University/Emory University & $42.58 / 39.50$ \\
\hline \multicolumn{6}{|c|}{ Panel B. Comparison of the top 10 Asia-Pacific universities with North American universities by total weighted article count in top 10 finance journals (Group 1) } \\
\hline 1 & Hong Kong University of Science and Technology & 37.50 & $16 / 17$ & University of North Carolina/Cornell University & $37.67 / 36.92$ \\
\hline 2 & University of New South Wales (Go8) & 20.83 & $43 / 44$ & Princeton University/University of Utah & $20.92 / 20.83$ \\
\hline 3 & National University of Singapore & 17.33 & $53 / 54$ & University of Iowa/University of South Carolina & $17.42 / 16.95$ \\
\hline 4 & Chinese University of Hong Kong & 16.08 & $57 / 58$ & Texas A\&M University/University of British Columbia & $16.70 / 15.92$ \\
\hline 5 & Hong Kong Polytechnic University & 14.58 & $62 / 63$ & Georgia State University/University of Oklahoma & $14.83 / 14.58$ \\
\hline 6 & City University of Hong Kong & 11.75 & $80 / 81$ & University of Missouri/Bentley College, MA & $11.83 / 11.33$ \\
\hline 7 & Nanyang Technological University & 10.67 & $84 / 85$ & Case Western Reserve University/Wake Forest University & $10.83 / 10.42$ \\
\hline 8 & Singapore Management University & 9.08 & $92 / 93$ & University of Western Ontario/Fordham University & $9.17 / 9.08$ \\
\hline 9 & Korea University & 8.75 & $94 / 95$ & University of Cincinnati/Texas Tech University & $9.08 / 8.75$ \\
\hline 10 & University of Hong Kong & 7.92 & 98/99 & University of Kansas/Concordia University & $8.08 / 7.83$ \\
\hline \multicolumn{6}{|c|}{ Panel C. Comparison of the top 10 Asia-Pacific universities with North American universities by total weighted article count in top 10 finance journals (Group 2) } \\
\hline 1 & Hong Kong University of Science and Technology & 35.00 & $16 / 17$ & Yale University/Cornell University & $36.67 / 34.58$ \\
\hline 2 & National University of Singapore & 12.00 & $64 / 65$ & University of Colorado/Louisiana State University & $12.00 / 11.83$ \\
\hline 3 & Chinese University of Hong Kong & 9.75 & $82 / 83$ & Washington State University/University of Oklahoma & $9.83 / 9.58$ \\
\hline 4 & Korea University & 9.75 & $82 / 83$ & Washington State University/University of Oklahoma & $9.83 / 9.58$ \\
\hline 5 & Hong Kong Polytechnic University & 8.92 & $86 / 87$ & Bentley College, MA/Babson College & $9.33 / 8.67$ \\
\hline 6 & University of New South Wales (Go8) & 8.67 & $87 / 88$ & Babson College/University of Central Florida & $8.67 / 8.33$ \\
\hline 7 & City University of Hong Kong & 7.92 & $91 / 92$ & Fordham University/North Carolina State University & $8.00 / 7.83$ \\
\hline 8 & University of Hong Kong & 6.92 & $94 / 95$ & George Mason University/California State University & $6.92 / 6.75$ \\
\hline 9 & Singapore Management University & 6.83 & $94 / 95$ & George Mason University/California State University & $6.92 / 6.75$ \\
\hline 10 & University of Melbourne (Go8) & 5.50 & $104 / 105$ & American University/Florida Atlantic University & $5.75 / 5.50$ \\
\hline \multicolumn{6}{|c|}{ Panel D. Comparison of the top 10 Asia-Pacific universities with North American universities by total weighted article count in the top 5 finance journals } \\
\hline 1 & Hong Kong University of Science and Technology & 26.83 & $16 / 17$ & Yale University/Emory University & $27.08 / 26.42$ \\
\hline 2 & National University of Singapore & 8.50 & $65 / 66$ & University of Cincinnati/Georgia Institute of Technology & $8.58 / 8.42$ \\
\hline 3 & Korea University & 7.42 & $71 / 72$ & University of South Carolina/Case Western Reserve University & $7.53 / 7.33$ \\
\hline 4 & Chinese University of Hong Kong & 7.17 & $72 / 73$ & Case Western Reserve University/University of Washington & $7.33 / 6.92$ \\
\hline 5 & University of Melbourne (Go8) & 5.17 & $84 / 85$ & Washington State University/Babson College & $5.33 / 5.17$ \\
\hline 6 & Singapore Management University & 5.00 & $87 / 88$ & University of Western Ontario/George Washington University & $5.08 / 5.00$ \\
\hline 7 & University of Hong Kong & 4.92 & $88 / 89$ & George Washington University/American University & $5.00 / 4.83$ \\
\hline 8 & Hong Kong Polytechnic University & 4.83 & $88 / 89$ & George Washington University/American University & $5.00 / 4.83$ \\
\hline 9 & Victoria University of Wellington & 3.50 & $99 / 100$ & Texas Christian University/University of Alabama & $3.38 / 3.33$ \\
\hline 10 & University of New South Wales (Go8) & 3.42 & $99 / 100$ & Texas Christian University/University of Alabama & $3.38 / 3.33$ \\
\hline
\end{tabular}

Notes: The top 10 Asia-Pacific universities are compared with universities in North America in terms of total weighted article count. The weights are by co-authorship and co-affiliation.

In Table 5, each of the top 10 Asia-Pacific institutions is matched against institutions in the United States and Canada that have similar scholarly output in terms of the total number of weighted articles. In Panel A of Table 5, in terms of weighted article count, the UNSW has a scholarly output (88.92) that corresponds to the scholarly output between that of Harvard 
University (92.20) and the University of Pennsylvania (85.87). Since Harvard University and the University Pennsylvania are ranked as 5th and 6th respectively (see column 4 of Table 5) among all institutions in the United States and Canada, UNSW would most likely have been able to achieve a similar rank by raw research output, if it was based in North America.

When examining Panel B of Table 5, it can be clearly seen that the UNSW who publish less frequently in the top US journals compared to HKUST, would achieve a US-equivalent rank if 43/44. In contrast, the top ranked HKUST is notably ranked better with a US-equivalent rank of 16/17 compared to the next best ranked National University of Singapore with a US-equivalent rank of 53/54. Of note, HKUST is able to consistently maintain is US-equivalent rank of 16/17 for a different top 10 finance journal group (see Panel C) and also for the more generally agreed top 5 finance journal group (see Panel D). This result suggests that academics at the HKUST are the most active in publishing in top US journals compared to other academics in the Asia-Pacific region. Table 5 also shows that the top 5 institutions in the Asia-Pacific region would have been able to achieve a scholarly output level comparable with at least US institutions that ranked within the top 24 (see Panel A); the top 63 (see Panel B); the top 87 (see Panel C); and the top 85 (see Panel D) in the North American region.

\subsection{Research productivity progress of the top 10 institutions}

Table 6 reports the research productivity progress between two sub-periods for several AsiaPacific institutions by weighted article count using 24 finance journals (Panel A); the top 10 finance journals in Group 1 (Panel B) and Group 2 (Panel C); and the top 5 finance journals (Panel D) over the entire sample period. The institutions analysed are those that achieve a rank that is within the top 10, based upon one or more of the four journal groups used. Applying this criterion, leads to the analysis of 15 Asia-Pacific institutions. For each of these institutions, their ranks based upon weighted article count for the entire sample period by the four journal groups are provided. The weighted article count in the first sub-period 2000-2003 and the second subperiod 2004-2007 for each institution is also provided. Additionally, the percentage change in weighted articles between the sub-periods is given. ${ }^{15}$

In Panel A of Table 6, we observe that 9 of the 15 institutions had a positive increase in scholarly output in all 24 finance journals. Only 4 or 26.67 percent of the 15 institutions had well over a 100 percent increase in scholarly output. These universities include Monash University, University of Queensland, Singapore Management University and the Victoria University of Wellington. A notable increase of 94.20 percent was also experienced by the University of Sydney. Despite the positive increases in research productivity by these universities, their number of weighted articles in the top 5 and top 10 finance journals (see Panels B, C and D) across the sub-periods are small when compared to HKUST. In Panel D of Table 6, the dominance of HKUST in its track record of publishing within the top 5 finance journals is evident, where it is the only institution that has a highest weighted article of 9.25 in the first sub-period 2000-2003 and 17.58 in the second sub period 2004-2007. Of note, it can be seen that the National University of Singapore and Singapore Management University have significantly improved their scholarly output in the top 5 finance journals across the two sub-periods (see Panel D). It is

\footnotetext{
${ }^{15}$ This study recognises that often research papers have lengthy review time, and publication lag is quite unpredictable. Taking this into account, we contend that ranking research productivity progress across two 4 year sub-periods is not too noisy to be meaningful. For example, Chan et. al. (2004) use a 5-year time frame in their study to measure research productivity progress.
} 
The Australasian Accounting Business \& Finance Journal, September, 2008. Jarnecic, Segara, Segara, and Westerholm: Scholarly Output Academics Asia-Pacific Finance.

Vol. 2, No.3. Page 40.

recognised that this tremendous positive increase is largely a reflection of coming off a small base. Nonetheless, this suggests that these two Singaporean universities are now starting to experience payoffs from their heavy investments to drive a research active culture. Of concern should be the Hong Kong Polytechnic University, which experienced a large decline of 73.91 percent in research productivity progress within the top 5 finance journals. Declines in research productivity based upon the top 5 finance journals are also experienced by the UNSW, University of Sydney, University of Melbourne and the University of Hong Kong. Table 6 serves to highlight a significant achievement of HKUST to maintain a consistent increase in research productivity progress in all the finance journal groups examined. Conversely, a decrease in research productivity progress is consistently experienced by Hong Kong Polytechnic University. By highlighting these trends, this study contributes to universities in their re-assessment of strategies designed to increase scholarly output.

Table 6

Research productivity progress of the top Asia-Pacific institutions from 2000 to 2007

\begin{tabular}{|c|c|c|c|c|c|c|c|c|c|c|}
\hline \multirow[b]{2}{*}{ Institution name } & \multicolumn{4}{|c|}{ Ranks based upon weighted article count for } & \multicolumn{3}{|c|}{ Panel A. All 24 finance journals } & \multicolumn{3}{|c|}{ Panel B. Top 10 finance journals (Group 1) } \\
\hline & $\begin{array}{l}\text { All } 24 \\
\text { finance } \\
\text { journals }\end{array}$ & $\begin{array}{l}\text { Top } 10 \\
\text { finance } \\
\text { journals } \\
\text { (Group 1) }\end{array}$ & $\begin{array}{l}\text { Top } 10 \\
\text { finance } \\
\text { journals } \\
\text { (Group 2) }\end{array}$ & $\begin{array}{c}\text { Top } 5 \\
\text { finance } \\
\text { journals }\end{array}$ & $2000-2003$ & 2004-2007 & $\% \Delta$ & $2000-2003$ & 2004-2007 & $\% \Delta$ \\
\hline University of New South Wales (Go8) & 1 & 2 & 6 & 10 & 35.92 & 53.00 & 47.56 & 7.33 & 13.50 & 84.09 \\
\hline Hong Kong University of Science and Technology & 2 & 1 & 1 & 1 & 29.58 & 30.92 & 4.51 & 14.25 & 23.25 & 63.16 \\
\hline University of Sydney (Go8) & 3 & & & & 18.67 & 36.25 & 94.20 & 3.67 & 2.25 & -38.64 \\
\hline Hong Kong Polytechnic University & 4 & 5 & 5 & 8 & 26.08 & 23.50 & -9.90 & 7.83 & 6.75 & -13.83 \\
\hline Monash University (Go8) & 5 & & & & 15.67 & 31.42 & 100.53 & 1.83 & 3.08 & 68.18 \\
\hline University of Melbourne (Go8) & 6 & & 10 & 5 & 21.75 & 22.50 & 3.45 & 4.67 & 2.83 & -39.29 \\
\hline University of Queensland (Go8) & 7 & & & & 11.92 & 28.92 & 142.66 & 0.00 & 3.83 & $\infty$ \\
\hline National University of Singapore & 8 & 3 & 2 & 2 & 16.50 & 24.17 & 46.46 & 4.67 & 12.67 & 171.43 \\
\hline Nanyang Technological University & 9 & 7 & & & 23.00 & 17.17 & -25.36 & 5.17 & 5.50 & 6.45 \\
\hline Chinese University of Hong Kong & 10 & 4 & 3 & 4 & 20.50 & 19.42 & -5.28 & 8.25 & 7.83 & -5.05 \\
\hline City University of Hong Kong & & 6 & 7 & & 15.92 & 14.17 & -10.99 & 6.50 & 5.25 & -19.23 \\
\hline Singapore Management University & & 8 & 9 & 6 & 4.00 & 9.75 & 143.75 & 1.33 & 7.75 & 481.25 \\
\hline Korea University & & 9 & 4 & 3 & 5.42 & 7.42 & 36.92 & 3.50 & 5.25 & 50.00 \\
\hline University of Hong Kong & & 10 & 8 & 7 & 6.83 & 11.33 & 65.85 & 3.67 & 4.25 & 15.91 \\
\hline \multirow[t]{2}{*}{ Victoria University of Wellington } & & & & 9 & 5.50 & 12.50 & 127.27 & 1.00 & 3.50 & 250.00 \\
\hline & & & & & \multicolumn{3}{|c|}{ Panel C. Top 10 finance journals (Group 2) } & \multicolumn{3}{|c|}{ Panel D. Top 5 finance journals } \\
\hline University of New South Wales (Go8) & 1 & 2 & 6 & 10 & 4.33 & 4.33 & 0.00 & 2.67 & 0.75 & -71.88 \\
\hline Hong Kong University of Science and Technology & 2 & 1 & 1 & 1 & 12.42 & 22.58 & 81.88 & 9.25 & 17.58 & 90.09 \\
\hline University of Sydney (Go8) & 3 & & & & 2.00 & 1.50 & -25.00 & 1.00 & 0.00 & -100.00 \\
\hline Hong Kong Polytechnic University & 4 & 5 & 5 & 8 & 6.67 & 2.25 & -66.25 & 3.83 & 1.00 & -73.91 \\
\hline Monash University (Go8) & 5 & & & & 0.83 & 1.33 & 60.00 & 0.50 & 1.00 & 100.00 \\
\hline University of Melbourne (Go8) & 6 & & 10 & 5 & 3.67 & 1.83 & -50.00 & 3.33 & 1.83 & -45.00 \\
\hline University of Queensland (Go8) & 7 & & & & 0.00 & 1.50 & $\infty$ & 0.00 & 1.50 & $\infty$ \\
\hline National University of Singapore & 8 & 3 & 2 & 2 & 3.17 & 8.83 & 178.95 & 0.67 & 7.83 & 1075.00 \\
\hline Nanyang Technological University & 9 & 7 & & & 1.58 & 2.83 & 78.95 & 0.83 & 2.50 & 200.00 \\
\hline Chinese University of Hong Kong & 10 & 4 & 3 & 4 & 4.75 & 5.00 & 5.26 & 3.42 & 3.75 & 9.76 \\
\hline City University of Hong Kong & & 6 & 7 & & 2.67 & 5.25 & 96.87 & 0.50 & 2.58 & 416.67 \\
\hline Singapore Management University & & 8 & 9 & 6 & 0.83 & 5.50 & 560.00 & 0.50 & 4.50 & 800.00 \\
\hline Korea University & & 9 & 4 & 3 & 4.50 & 5.25 & 16.67 & 3.50 & 3.92 & 11.90 \\
\hline University of Hong Kong & & 10 & 8 & 7 & 3.33 & 3.58 & 7.50 & 2.83 & 2.08 & -26.47 \\
\hline Victoria University of Wellington & & & & 9 & 1.00 & 2.50 & 150.00 & 1.00 & 2.50 & 150.00 \\
\hline
\end{tabular}

Notes:

The table shows the progress of research productivity of the top 10 Asia-Pacific institutions between two sub-periods: 2000-2003 and 20042007. Research productivity is measured by total weighted article count published by these institutions in 24 finance journals (Panel A); the top 10 finance journals based upon Oltheten et. al., 2005 (Panel B); the top 10 finance journals based upon Chen and Huang, 2007 (Panel C) and the top 5 finance journals (Panel D). The percentage change in total weighted article count between the sub-periods is presented.

\subsection{Ranking of authors}

Table 7 lists the ranking of the top 10 authors in the Asia-Pacific region by their total weighted articles in 24 finance journals (Panel A); the top 10 finance journals in Group 1 (Panel B) and Group 2 (Panel C); and the top 5 finance journals (Panel D) over the entire sample period. For each top ranked author, the table also provides their total number of unweighted articles as well as the number of articles contributed by that author to each finance journal group examined. In Panel A of Table 6, four of the top five authors are from Australian universities and include Robert Faff, Alex Frino, David Gallagher and Fariborz Moshirian. Of these top five authors, 
three do not contribute articles to the top 5 finance journals, where the two remaining authors contribute only a small fraction of their total research output to the top 5 finance journals. This result might be misinterpreted to suggest that these authors are focused towards quantity of publications over quality. However, we contend that in general most academics in the AsiaPacific region are less likely to publish in the top US journals as their research articles are aligned to specific research areas in non-US regions, which complement the editorial needs of regional and/or specialised journals outside the top 10 finance journal list.

This argument is supported by examining the research profile of Alex Frino and David Gallagher, who specialise in the research areas of futures markets and funds management, respectively. Given both these authors specialisation in finance and their regional research focus, their research tends to be published in journals outside the top 10. In Panel B of Table 7, six of the top 10 authors in the Asia-Pacific region are from HKUST, where the total number of authors in the top 10 list from HKUST increases to seven based upon the top 10 finance journals (group 2). From Panel C of Table 7, all of the top five authors are from HKUST and include Kalok Chan, Vidhan Goyal, Jie Gan, Joseph Fan and Sudipto Dasgupta. These five authors contribute from 66.67 percent to 99.09 percent to the top 5 finance journals.

This suggests that academics from HKUST are more likely to publish in top US journals, relative to other universities in the Asia-Pacific region. This perhaps reflects the research culture of HKUST to encourage academics to publish more in perceived quality journals rather than lesser journals. This is consistent with the hiring policy of HKUST to solely recruit academic scholars who hold $\mathrm{PhDs}$ from internationally-acclaimed universities. Notably, the most prolific author in the Asia-Pacific region is Chan Kalok (see Panel D), where he has published 3.67 times more publications in the top 5 finance journals than the next best ranked author. Of Chan Kalok's 17 publications in the 24 finance journals examined, a significant $64.71 \%$ were published in the top 5 finance journals.

Comparing Table 1 with Panel A of Table 7, it is interesting to note that 4 out of the top 10 institutions do not employ any of the top 10 authors. ${ }^{16}$ A similar comparison of the top 10 institutions based upon varying journal groups (Table 2 to 4 ) with the top 10 author list (Table 7) reveals that at least 6 out of the top 10 institutions do not employ any of the top 10 authors. In general, this suggests that these institutions have made it into the top 10 Asia-Pacific institutions based on the group effort of their research active staff. Is it noteworthy to mention that HKUST that is top ranked from Tables 2 to 4 , has a larger proportion of authors from the top 10 list compared to other institutions in the top 10.

Also, we find that some institutions such as the UNSW, which is ranked as number one in Table 1, has only two of its authors in the top 10 list (see Panel A of Table 7). This result indicates that a majority of the top 10 Asia-Pacific institutions may have been included in that list primarily due to the research efforts of a few research active staff members or an individual research active staff member employed by that institution. We examine this issue in detail in the next section.

16 These institutions include: the University of Melbourne; University of Queensland; Nanyang Technological University; and the Chinese University of Hong Kong. 
The Australasian Accounting Business \& Finance Journal, September, 2008. Jarnecic, Segara, Segara, and Westerholm: Scholarly Output Academics Asia-Pacific Finance.

Table 7

The top 10 authors in Asia-Pacific institutions ranked by total weighted articles from 2000 to 2007.

\begin{tabular}{|c|c|c|c|c|c|c|c|c|}
\hline \multirow{2}{*}{ Rank } & \multirow{2}{*}{ Author } & \multirow{2}{*}{ Institution name } & \multirow{2}{*}{$\begin{array}{c}\text { Weighted } \\
\text { articles }\end{array}$} & \multirow{2}{*}{$\begin{array}{l}\text { Unweighted } \\
\text { articles }\end{array}$} & \multicolumn{4}{|c|}{$\begin{array}{l}\text { Number of weighted articles contributed by } \\
\text { each author based upon: }\end{array}$} \\
\hline & & & & & $\begin{array}{l}\text { Top } 24 \\
\text { finance } \\
\text { journals }\end{array}$ & $\begin{array}{c}\text { Top 10 } \\
\text { finance } \\
\text { journals } \\
\text { (Group 1) }\end{array}$ & $\begin{array}{c}\text { Top 10 } \\
\text { finance } \\
\text { journals } \\
\text { (Group 2) }\end{array}$ & $\begin{array}{c}\text { Top } 5 \\
\text { finance } \\
\text { journals }\end{array}$ \\
\hline \multicolumn{9}{|c|}{ Panel A. The top 10 authors in Asia-Pacific institutions ranked by total weighted count in 24 finance journals } \\
\hline 1 & Faff, Robert W & Monash University & 18.00 & 40 & 18.00 & 2.42 & 1.17 & 0.50 \\
\hline 2 & Frino, Alex & The University of Sydney & 10.33 & 27 & 10.33 & 1.17 & 0.00 & 0.00 \\
\hline 3 & Gallagher, David R & University of New South Wales & 8.58 & 17 & 8.58 & 0.00 & 0.00 & 0.00 \\
\hline 4 & Wang, Changyun $\mathrm{K}$ & National University of Singapore & 7.17 & 9 & 7.17 & 1.83 & 0.00 & 0.00 \\
\hline 5 & Moshirian, Fariborz & University of New South Wales & 7.08 & 11 & 7.08 & 6.75 & 0.25 & 0.25 \\
\hline 6 & Tong, Wilson HS & Hong Kong University of Science \& Technology & 7.00 & 14 & 7.00 & 2.50 & 1.67 & 0.83 \\
\hline 7 & Lally, Martin & Victoria University of Wellington & 6.50 & 8 & 6.50 & 0.00 & 0.00 & 0.00 \\
\hline 8 & Fung, Joseph KW & Hong Kong Baptist University & 6.00 & 12 & 6.00 & 0.33 & 0.33 & 0.00 \\
\hline 9 & Rui, Oliver M & The Hong Kong Polytechnic University & 6.00 & 17 & 6.00 & 2.25 & 1.08 & 0.50 \\
\hline 10 & Chan, Kalok & Hong Kong University of Science \& Technology & 5.92 & 17 & 5.92 & 4.58 & 4.58 & 3.92 \\
\hline \multicolumn{9}{|c|}{ Panel B. The top 10 authors in Asia-Pacific institutions ranked by total weighted count in the top 10 finance journals (Group 1) } \\
\hline 1 & Moshirian, Fariborz & University of New South Wales & 6.75 & 10 & 7.08 & 6.75 & 0.25 & 0.25 \\
\hline 2 & Chan, Kalok & Hong Kong University of Science \& Technology & 4.58 & 13 & 5.92 & 4.58 & 4.58 & 3.92 \\
\hline 3 & Goyal, Vidhan K & Hong Kong University of Science \& Technology & 3.33 & 6 & 3.33 & 3.33 & 3.33 & 1.83 \\
\hline 4 & Sun, Qian & Nanyang Technological University & 3.00 & 7 & 5.50 & 3.00 & 1.33 & 0.50 \\
\hline 4 & Gan, Jie & Hong Kong University of Science \& Technology & 3.00 & 3 & 3.00 & 3.00 & 3.00 & 3.00 \\
\hline 6 & Fan, Joseph PH & Hong Kong University of Science \& Technology & 2.58 & 5 & 2.83 & 2.58 & 2.58 & 1.58 \\
\hline 7 & Tong, Wilson HS & Hong Kong University of Science \& Technology & 2.50 & 6 & 7.00 & 2.50 & 1.67 & 0.83 \\
\hline 7 & Wu, Xueping & City University of Hong Kong & 2.50 & 4 & 3.50 & 2.50 & 1.00 & 0.50 \\
\hline 7 & Wu, YiLin & Hong Kong University of Science \& Technology & 2.50 & 3 & 3.50 & 2.50 & 2.00 & 1.00 \\
\hline 10 & Faff, Robert W & Monash University & 2.42 & 6 & 18.00 & 2.42 & 1.17 & 0.50 \\
\hline \multicolumn{9}{|c|}{ Panel C. The top 10 authors in Asia-Pacific institutions ranked by total weighted count in the top 10 finance journals (Group 2) } \\
\hline 1 & Chan, Kalok & Hong Kong University of Science \& Technology & 4.58 & 13 & 5.92 & 4.58 & 4.58 & 3.92 \\
\hline 2 & Goyal, Vidhan K & Hong Kong University of Science \& Technology & 3.33 & 6 & 3.33 & 3.33 & 3.33 & 1.83 \\
\hline 3 & Gan, Jie & Hong Kong University of Science \& Technology & 3.00 & 3 & 3.00 & 3.00 & 3.00 & 3.00 \\
\hline 4 & Fan, Joseph PH & Hong Kong University of Science \& Technology & 2.58 & 5 & 2.83 & 2.58 & 2.58 & 1.58 \\
\hline 5 & Dasgupta. Sudipto & Hong Kong University of Science \& Technology & 2.17 & 5 & 2.17 & 2.17 & 2.17 & 0.67 \\
\hline 6 & Grundy, Bruce D & University of Melbourne & 2.00 & 3 & 2.00 & 2.00 & 2.00 & 2.00 \\
\hline 6 & Cho, Jin-Wan & Korea University & 2.00 & 3 & 2.00 & 2.00 & 2.00 & 0.50 \\
\hline 6 & Wu, YiLin & Hong Kong University of Science \& Technology & 2.00 & 2 & 3.50 & 2.50 & 2.00 & 1.00 \\
\hline 6 & Isagawa, Nobuyuki & Kobe University & 2.00 & 2 & 4.83 & 2.00 & 2.00 & 0.00 \\
\hline 10 & $\mathrm{Bae}, \mathrm{KH}$ & Hong Kong University of Science \& Technology & 2.00 & 6 & 2.25 & 1.67 & 2.00 & 1.67 \\
\hline \multicolumn{9}{|c|}{ Panel D. The top 10 authors in Asia-Pacific institutions ranked by total weighted count in the top 5 finance journals } \\
\hline 1 & Chan, Kalok & Hong Kong University of Science \& Technology & 3.92 & 11 & 5.92 & 4.58 & 4.58 & 3.92 \\
\hline 2 & Gan, Jie & Hong Kong University of Science \& Technology & 3.00 & 3 & 3.00 & 3.00 & 3.00 & 3.00 \\
\hline 3 & Grundy, Bruce D & University of Melbourne & 2.00 & 3 & 2.00 & 2.00 & 2.00 & 2.00 \\
\hline 4 & Hameed, Allaudeen & National University of Singapore & 2.00 & 5 & 3.00 & 2.00 & 2.00 & 2.00 \\
\hline 5 & Goyal, Vidhan K & Hong Kong University of Science \& Technology & 1.83 & 4 & 3.33 & 3.33 & 3.33 & 1.83 \\
\hline 5 & Chung, San-Lin & National Central University at Taiwan & 1.83 & 3 & 5.33 & 1.83 & 1.83 & 1.83 \\
\hline 7 & $\mathrm{Bae}, \mathrm{KH}$ & Hong Kong University of Science \& Technology & 1.67 & 5 & 2.25 & 1.67 & 2.00 & 1.67 \\
\hline 8 & Lang, Larry HP & Chinese University of Hong Kong & 1.58 & 4 & 2.42 & 1.83 & 1.58 & 1.58 \\
\hline 8 & Fan, Joseph PH & Hong Kong University of Science \& Technology & 1.58 & 4 & 2.83 & 2.58 & 2.58 & 1.58 \\
\hline 10 & Hwang, Chuan-Yang & Nanyang Technological University & 1.50 & 3 & 1.83 & 1.50 & 1.83 & 1.50 \\
\hline
\end{tabular}

Notes:

This table reports the productivity of the top 10 authors in Asia-Pacific institutions ranked by their total weighted article count in 24 finance journals (Panel A); the top 10 finance journals based upon Oltheten et. al., 2005 (Panel B); the top 10 finance journals based upon Chen and Huang, 2007 (Panel C) and the top 5 finance journals (Panel D). The number of weighted articles contributed by each author for the various groups of finance journal analysed is also provided.

\subsection{Research Productivity Dependency for each of the top 10 institutions}

To address how dependent an institution is on the research productivity of key members of its research staff, an examination of the Research Productivity Dependency (RPD) index is performed. For each institution examined, the RPD index is computed for four 2-year subperiods within the sample period 2000-2007. Table 8 reports the RPD index for each sub-period and the percentage change in this index across (i) 2000-2001 to 2002-2003; (ii) 2002-2003 to 2003-2004; and (iii) 2004-2005 to 2006-2007. The institutions analysed are those that achieve a rank that is 
The Australasian Accounting Business \& Finance Journal, September, 2008. Jarnecic, Segara, Segara, and Westerholm: Scholarly Output Academics Asia-Pacific Finance.

Vol. 2, No.3. Page 43.

within the top 10, based upon one or more of the four journal groups used. Applying this criterion, leads to the analysis of 15 Asia-Pacific institutions. For each of these institutions, their ranks based upon weighted article count for the entire sample period by the four journal groups are provided. In addition, summary statistics of the RPD index for all institutions analysed are provided for each sub-period in our sample period.

Table 8

Dependency of research staff members from the top Asia-Pacific institutions from 2000 to 2007

\begin{tabular}{|c|c|c|c|c|c|c|c|c|c|c|c|}
\hline \multirow[b]{2}{*}{ Institution name } & \multicolumn{4}{|c|}{ Ranks based upon weighted article count for } & \multicolumn{4}{|c|}{$\begin{array}{l}\text { Research Productivity Dependency } \\
\text { (RPD) index }\end{array}$} & \multicolumn{3}{|c|}{ Percentage change in $R P D$} \\
\hline & $\begin{array}{l}\text { All } 24 \\
\text { finance } \\
\text { journals }\end{array}$ & $\begin{array}{l}\text { Top } 10 \\
\text { finance } \\
\text { journals } \\
\text { (Group 1) }\end{array}$ & $\begin{array}{l}\text { Top } 10 \\
\text { finance } \\
\text { journals } \\
\text { (Group 2) }\end{array}$ & $\begin{array}{c}\text { Top } 5 \\
\text { finance } \\
\text { journals }\end{array}$ & $\begin{array}{c}2000 \\
\text { to } \\
2001\end{array}$ & $\begin{array}{c}2002 \\
\text { to } \\
2003\end{array}$ & $\begin{array}{c}2004 \\
\text { to } \\
2005\end{array}$ & $\begin{array}{c}2006 \\
\text { to } \\
2007\end{array}$ & $\begin{array}{c}2000-01 \\
\text { to } \\
2002-03\end{array}$ & $\begin{array}{c}2002-03 \\
t o \\
2003-04\end{array}$ & $\begin{array}{c}2004-05 \\
t o \\
2006-07\end{array}$ \\
\hline University of New South Wales (Go8) & 1 & 2 & 6 & 10 & 0.734 & 0.521 & 0.657 & 1.102 & -29.01 & 26.06 & 67.72 \\
\hline Hong Kong University of Science \& Technology & 2 & 1 & 1 & 1 & 0.922 & 0.545 & 0.533 & 0.695 & -40.88 & -2.23 & 30.51 \\
\hline University of Sydney (Go8) & 3 & & & & 0.934 & 0.586 & 1.176 & 0.903 & -37.28 & 100.63 & -23.18 \\
\hline Hong Kong Polytechnic University & 4 & 5 & 5 & 8 & 0.602 & 0.808 & 0.637 & 0.969 & 34.24 & -21.25 & 52.18 \\
\hline Monash University (Go8) & 5 & & & & 0.848 & 1.034 & 1.410 & 1.398 & 21.92 & 36.39 & -0.84 \\
\hline University of Melbourne (Go8) & 6 & & 10 & 5 & 0.557 & 0.712 & 0.451 & 0.520 & 27.89 & -36.71 & 15.29 \\
\hline University of Queensland (Go8) & 7 & & & & 0.208 & 0.633 & 0.763 & 0.679 & 204.67 & 20.40 & -10.91 \\
\hline National University of Singapore & 8 & 3 & 2 & 2 & 0.353 & 1.259 & 0.780 & 0.366 & 256.23 & -38.07 & -53.06 \\
\hline Nanyang Technological University & 9 & 7 & & & 0.688 & 0.922 & 0.669 & 0.491 & 33.94 & -27.41 & -26.71 \\
\hline Chinese University of Hong Kong & 10 & 4 & 3 & 4 & 0.496 & 0.695 & 0.576 & 0.641 & 39.99 & -17.15 & 11.32 \\
\hline City University of Hong Kong & & 6 & 7 & & 0.550 & 0.627 & 0.423 & 0.535 & 14.13 & -32.60 & 26.58 \\
\hline Singapore Management University & & 8 & 9 & 6 & $\mathrm{n} / \mathrm{a}$ & 0.399 & 0.499 & 0.569 & - & 25.21 & 14.11 \\
\hline Korea University & & 9 & 4 & 3 & $\mathrm{n} / \mathrm{a}$ & 0.716 & 0.667 & 0.517 & - & -6.86 & -22.44 \\
\hline University of Hong Kong & & 10 & 8 & 7 & 0.509 & 0.354 & 0.781 & 0.557 & -30.56 & 120.79 & -28.71 \\
\hline \multirow[t]{4}{*}{ Victoria University of Wellington } & & & & 9 & 0.000 & 0.547 & 1.047 & 0.730 & - & 91.32 & -30.22 \\
\hline & & & & Minimum & 0.000 & 0.354 & 0.423 & 0.366 & & & \\
\hline & & & & Maximum & 0.934 & 1.259 & 1.410 & 1.398 & & & \\
\hline & & & & Mean & 0.569 & 0.691 & 0.738 & 0.712 & & & \\
\hline
\end{tabular}

Notes:

The table shows the annual dependency of research staff members from the top 10 Asia-Pacific universities for the period 2000 to 2007 . The higher(lower) the research productivity dependency (RPD) index means that there is more(less) dependency on a few research orientated staff members in the same university to publish in the top 24 finance journals. The RPD index is reported as not available (i.e. ' $\mathrm{n} / \mathrm{a}$ ') when the number of unweighted articles for the institution examined for that year is less than or equal to one and/or the number of active researchers for the university in that year examined is less than or equal to one.

As discussed in Section 2.3, a low (high) RPD index means that there is less (more) dependency on a few research orientated staff members in the same institution to publish in the top 24 finance journals. Ideally, institutions should aim for a low RPD index. The National University of Singapore has the lowest RPD index in 2006-2007, which has consistently reduced over the last two sub-periods. Conversely, three universities for the sub-period 2006-2007 are found with an RPD index value that is higher than the mean, and which did not marginally change or increased from the previous period. These universities include the UNSW, Hong Kong Polytechnic University and Monash University. Out of these three institutions, Monash University has the highest RPD index for both the two sub-periods of 2004-2005 and 2006-2007. This indicates that Monash University is reliant on one or a few number of academics to actively produce finance publications. This observation is supported in Panel A of Table 7, where Robert Faff from Monash University is ranked as the most productive finance researcher in the Asia-Pacific region. From Panel A of Table 6, it is interesting to note that Monash University had a 100.53 percent increase in scholarly output between 2000-2003 and 2004-2007. This improvement coincides with the appointment of Robert Faff in February 2002. Notably, the top ranked institution (i.e., HKUST) has effectively managed to maintain its RPD index, in line with the mean RPD index of 15 institutions across the last three sub-periods. This result suggests that HKUST has a research publication culture that is embraced by many of its academics. Overall, the RPD index is an 
The Australasian Accounting Business \& Finance Journal, September, 2008. Jarnecic, Segara, Segara, and Westerholm: Scholarly Output Academics Asia-Pacific Finance.

Vol. 2, No.3. Page 44.

extremely useful "alert" tool, which aids an institution's risk assessment of its dependency on too few productive research staff.

\section{Concluding remarks}

This study ranks the scholarly output among leading Asia-Pacific institutions and their academic research staff using set of 24 finance journals during 2000 to 2007. These ranks are compared and contrasted to the ranks based upon three groups of finance journals groups, each of which vary in perceived journal quality. This analysis is designed to help university executive management, government policy, funding bodies, academic staff and future students in better assessing research performance. The number of weighted articles, which facilitates adjustments for coauthorships and co-affiliations, is used as the primary measure of scholarly output. Weighted JFequivalent pages counts, which also provide a measure for standardising different fonts and article lengths, together with unweighted articles are also reported. The ranks based upon JFequivalent pages are provided only for reference, as prior studies use these measures. A total of 300 institutions are ranked. An interesting finding is that several of the long-established Go8 Australian universities are ranked in the top 20 institutions in the Asia-Pacific region. Conversely, the 'traditional' long-standing universities in Asia are not ranked in the top 20 institutions. These results suggest that school history and tradition alone will not improve scholarly output. Instead, universities (i.e., whether 'traditional' or 'newer') that promote a culture of intellectual and research excellence enhance their research publication profile, thereby improving their regional and international standing among their peers. The results show that the scholarly output of the top Asia-Pacific institutions based upon 24 finance journals is comparable to their North American counterparts. For example, the scholarly output of the top 5 institutions in the Asia-Pacific region is comparable with at least the top 24 major institutions in the United States and Canada. However, for the top 5 institutions based upon the top 5 finance journals, the US-equivalent rank drops to 85 . This indicates that the top 5 institutions in the Asia-Pacific region are less likely to publish in top US journals than universities in the North American region. We find that the distribution of scholarly output based upon all finance journals groups across the Asia-Pacific institutions examined is highly skewed. Our study also develops the Research Productivity Dependency (RPD) index, which aids an institution's risk assessment of its dependency on too few productive research staff. Future studies in this direction are encouraged for other disciplines in the Asia-Pacific region (e.g., engineering, business law, science) to gauge their overall research productivity at both the regional level and international level. Also, a future study analysing how university rankings change with the removal of key research active academic staff would be valuable to university executive management for recruitment and performance evaluation decisions. 


\section{References}

Alexander, J.C., Mabry, R.H., 1994. Relative significance of journals, authors, and articles cited in financial research. Journal of Finance 49(2), 697-712.

https://doi.org/10.1111/j.1540-6261.1994.tb05158.x

Bakir, A., Vitell, S.J., Rose, G.M., 2000. Publications in major marketing journals: An analysis of scholars and marketing departments. Journal of Marketing Education 22(2), 99-107. https://doi.org/10.1177/0273475300222004

Borokhovich, K.A., Bricker, R.J., Brunarski, K.R., Simkins, B.S., 1995. Finance research productivity and influence. Journal of Finance 50(5), 1691-1717. https://doi.org/10.1111/j.1540-6261.1995.tb05193.x

Brinn, A., Jones, M.J., Pendlebury, M., 1996. 'UK Accounts' Perceptions of research journal quality. Accounting and Business Research (Summer), 265-278. https://doi.org/10.1080/00014788.1996.9729516

Brown, L.D., 1996. Influential accounting articles, individuals, Ph.D. granting institutions and faculties: A citational analysis. Accounting Organizations and Society 21(7/8), 723-754. https://doi.org/10.1016/0361-3682(96)00012-8

Brown, L.D., Gardner, J.C., 1985. Applying citation analysis to evaluate the research contributions of accounting faculty and doctoral programs. The Accounting Review 60(2), 262-277.

Chan, K.C., Chen, C.R, Steiner, T.L., 2001. Research productivity of the finance profession in the Asia-Pacific region. Pacific-Basin Finance Journal 9(3), 265-280. https://doi.org/10.1016/S0927-538X(01)00011-7

Chan, K.C., Chen, C.R., Steiner, T.L., 2004. Who is publishing? An analysis of finance research productivity in the European Region. Journal of Business Finance \& Accounting 31(3/4), 401437. https://doi.org/10.1111/j.0306-686X.2004.00545.x

Chan, K.C., Chen, C.R., Lung, P.P., 2005. Ranking of finance programs in the Asia-Pacific region: An update. Pacific-Basin Finance Journal 13(5), 584-600. https://doi.org/10.1016/j.pacfin.2005.05.001

Chan, K.C., Chen, C.R., Cheng, L.T.W., 2007. Global ranking of accounting programmes and the elite effect in accounting research. Accounting and Finance 47(2), 187-220. https://doi.org/10.1111/j.1467-629X.2007.00234.X

Chen, K.C., Huang, Y., 2007. Author affiliation index, finance journal ranking, and the pattern of authorship. Journal of Corporate Finance 13(5), 1008-1026. https://doi.org/10.1016/j.jcorpfin.2007.04.011

Cheng, L.T.W., Chan, K.C., Chan, R.Y.K., 2003. Publications in major marketing journals: An analysis of research productivity of Asia-Pacific universities. Journal of Marketing Education 25(2), 163-176. https://doi.org/10.1177/0273475303254023

Collins, J.T., Cox R.G., Stango, V., 2000. The publishing patterns of recent economics Ph.D. recipient. Economic Enquiry 38(2), 358-367. https://doi.org/10.1111/j.1465-7295.2000.tb00023.x

Fahey, S. 2007. Keynote address: Rethinking international education engagement in the Asia Pacific region. Pacific Economic Cooperation Conference: Managing the challenges of growth (Sydney, April 2007), weblink: www.monash.edu.au/international/dvc/peccspeech.pdf

French, N., Massy, W., Young, K., 2001. Research assessment in Hong Kong. Higher Education 42(1), 35-46.

Jin, J.C., Yau, L., 1999. Research productivity of the economics profession in East Asia. Economic Inquiry 37(4), 706-710. https://doi.org/10.1111/j.1465-7295.1999.tb01458.x 
Lindsey, D., 1980. Production and citation measure in the sociology of science: The problem of multiple authorship. Social Studies of Science 10, 145-162. https://doi.org/10.1177/030631278001000202

Maberly, Edwin D. and Pierce, Raylene M., 2007. Citation patterns within the leading top-tier finance journals: Implications for journal rankings and other issues" (November 1, 2007). Available at SSRN: http://ssrn.com/abstract $=1026522$. https://doi.org/10.2139/ssrn.1026522

MacRoberts, M.H., MacRoberts, B.R., 1989. Problems of citation analysis: A critical review. Journal of the American Society for Information Science 40(5), 342-349. https://doi.org/10.1002/(SICI) 1097-4571(198909)40:5<342::AID-ASI7>3.0.CO;2-U

MacRoberts, M.H., MacRoberts, B.R., 1996. Problems of citation analysis. Scientometrics 36(3), 435-444. https://doi.org/10.1007/BF02129604

Moore, L.J., Taylor, B.W., 1980. A study of institutional publications in business-related academic journals, 1972-1978. Quarterly Review of Economics and Business 20 (Spring), 8797.

Neuhaus, C., Neuhaus, E., Asher, A., Wrede, C., 2006. The depth and breadth of Google Scholar: An empirical study. Portal: Libraries and the Academy 6(2), 127-141. https://doi.org/10.1353/pla.2006.0026

Niemi, A.W., Jr., 1987. Institutional contributions to the leading finance journals, 1975-1986: A note. Journal of Finance 42(5), 1389-1397. https://doi.org/10.1111/j.1540-6261.1987.tb04374.x

Niemi, A.W., Jr., 1988. Publications performance of marketing departments, 1975-1985. Journal of Marketing Education 10(2), 8-12. https://doi.org/10.1177/027347538801000203

Nolan, A., 2005. Research-teaching linkages: a common agenda, in Academy Exchange. The Higher Education Academy Issue 2 Autumn, 20-21.

Oltheten, E., Theoharakis, V., Travlos, N.G., 2005. Faculty perceptions and readership patters of finance journals: A global view. Journal of Financial and Quantitative Analysis 40(1), 223239. https://doi.org/10.1017/S0022109000001800

Organisation for Economic Cooperation and Development (2007), Education at a glance report OECD Indicators 2007, Paris.

Pierce, B., Garven, G., 1995. Publishing international business research: A survey of leading journals. Journal of International Business Research 26(1), 69-89. https://doi.org/10.1057/palgrave.jibs.8490166

Reed, K.L., 1995. Citation analysis of faculty publications: Beyond Science Citation Index and Social Science [sic] Citation Index. Bulletin of the Medical Library Association 83(4), 503 508.

Scott, L.C., Mitias, P.M., 1996. Trends in rankings of economics departments in the U.S: An update. Economic Inquiry 34(2), 378-400. https://doi.org/10.1111/j.1465-7295.1996.tb01383.x

Seglen, P.O., 1998. Citation rates and journal impact factors are not suitable for evaluation of research. Acta Orthopaedica Scandinavica 69(3), 224-229. https://doi.org/10.3109/17453679809000920

The Australian (January 23, 2005, p.33), Accord a magnet for star recruits.

The Australian (January 23, 2005, p.35), Curtin to cut 150 lecturers.

Udell, G.G., Parker, S., Pettijohn, C., 1995. An examination of the research productivity of marketing faculty at newly minted AACSB schools. Journal of Marketing Theory and Practice 3(2), 106-113. https://doi.org/10.1080/10696679.1995.11501689

von Tunzelmann, N., Mbula, E. K., 2003. Changes in research assessment practices in other countries since 1999: final report. Social Policy Research Unit (University of Sussex), Higher Education Funding Council for England. 
The Australasian Accounting Business \& Finance Journal, September, 2008. Jarnecic, Segara, Segara, and Westerholm: Scholarly Output Academics Asia-Pacific Finance.

Vol. 2, No.3. Page 47.

Wallin, J. A., 2005. Bibliometric methods: Pitfalls and possibilities. Basic \& Clinical Pharmacology \& Toxicology 97(5), 261-275.

https://doi.org/10.1111/j.1742-7843.2005.pto_139.x

Weber, R.P., Stevenson, W.C., 1981. Evaluations of accounting journal and department quality. The Accounting Review 56(3), 596-612.

Williams, R., Van Dyke, N., 2004. The international standing of Australian universities. Melbourne Institute of Applied Economic and Social Research, The University of Melbourne, $1-27$.

Woodhall, M., 1999. Higher education in Asia, Amsterdam, Elsevier Science. 
The Australasian Accounting Business \& Finance Journal, September, 2008. Jarnecic, Segara, Segara, and Westerholm: Scholarly Output Academics Asia-Pacific Finance.

Vol. 2, No.3. Page 48.

\section{Appendix 1}

Asia-Pacific institutions that are ranked from 21 to 50 in finance research productivity

\begin{tabular}{|c|c|c|c|c|c|c|}
\hline Rank & Institution name & Country & $\begin{array}{l}\text { Weighted } \\
\text { articles }\end{array}$ & $\begin{array}{l}\text { Unweighted } \\
\text { articles }\end{array}$ & $\begin{array}{l}\text { Weighted } \\
\text { JF - Pages }\end{array}$ & $\begin{array}{c}\text { Rank based on } \\
\text { Weighted JF-Pages }\end{array}$ \\
\hline \multicolumn{7}{|c|}{ Panel A. The top 21 to 50 Asia-Pacific institutions ranked by total weighted count in 24 finance journals } \\
\hline 21 & Hong Kong Baptist University & Hong Kong & 15.33 & 35 & 285.95 & 22 \\
\hline 22 & Singapore Management University & Singapore & 13.75 & 33 & 269.53 & 23 \\
\hline 23 & Korea University & Korea & 12.83 & 29 & 317.14 & 21 \\
\hline 24 & Queensland University of Technology & Australia & 11.67 & 24 & 222.01 & 26 \\
\hline 25 & Griffith University & Australia & 11.25 & 20 & 205.34 & 27 \\
\hline 26 & National Central University, Taiwan & Taiwan & 11.17 & 23 & 235.85 & 25 \\
\hline 27 & National Chengchi University & Taiwan & 10.25 & 26 & 195.41 & 29 \\
\hline 28 & Macquarie University & Australia & 10.17 & 24 & 193.75 & 30 \\
\hline 29 & Korea Advanced Institute of Science and Technology & Korea & 10.00 & 24 & 236.42 & 24 \\
\hline 30 & University of Newcastle & Australia & 9.75 & 19 & 164.88 & 31 \\
\hline 31 & Yonsei University & Korea & 8.25 & 19 & 204.97 & 28 \\
\hline 32 & Yuan Ze University & Taiwan & 8.17 & 25 & 151.73 & 35 \\
\hline 33 & Edith Cowan University & Australia & 7.83 & 12 & 159.61 & 33 \\
\hline 34 & Tamkang University & Taiwan & 7.50 & 15 & 154.62 & 34 \\
\hline 35 & National Chung Cheng University & Taiwan & 6.75 & 16 & 130.39 & 37 \\
\hline 36 & Kobe University & Japan & 6.67 & 11 & 129.94 & 38 \\
\hline 37 & La Trobe University & Australia & 6.33 & 11 & 139.45 & 36 \\
\hline 37 & University of South Australia & Australia & 6.33 & 9 & 122.86 & 41 \\
\hline 39 & National Kaohsiung First University of Science \& Tech & Taiwan & 6.00 & 10 & 106.18 & 47 \\
\hline 39 & Kyoto University & Japan & 6.00 & 7 & 117.88 & 42 \\
\hline 41 & Hitotsubashi University & Japan & 5.67 & 9 & 164.11 & 32 \\
\hline 42 & Fu-Jen Catholic University & Taiwan & 5.67 & 16 & 112.17 & 44 \\
\hline 43 & Australian Prudential Regulation Authority (APRA) & Australia & 5.17 & 13 & 79.49 & 56 \\
\hline 44 & University of Otago & New Zealand & 5.08 & 15 & 106.62 & 46 \\
\hline 45 & Bond University & Australia & 5.00 & 8 & 102.37 & 48 \\
\hline 45 & Hong Kong Institute for Monetary Research & Hong Kong & 5.00 & 8 & 59.69 & 66 \\
\hline 47 & Curtin University of Technology & Australia & 4.92 & 11 & 113.39 & 43 \\
\hline 48 & Murdoch University & Australia & 4.75 & 13 & 68.98 & 60 \\
\hline 49 & Hanyang University & Korea & 4.62 & 11 & 124.74 & 40 \\
\hline 50 & Tsinghua University & China & 4.58 & 12 & 74.52 & 58 \\
\hline \multicolumn{7}{|c|}{ Panel B. The top 21 to 50 Asia-Pacific institutions ranked by total weighted count in the top 10 finance journals (Group 1) } \\
\hline 21 & University of Auckland & New Zealand & 3.25 & 8 & 72.65 & 24 \\
\hline 22 & Kobe University & Japan & 3.17 & 5 & 74.17 & 22 \\
\hline 23 & Royal Melbourne Institute of Technology (RMIT) & Australia & 3.08 & 7 & 51.36 & 30 \\
\hline 24 & Hitotsubashi University & Japan & 2.83 & 4 & 78.93 & 21 \\
\hline 25 & National Central University, Taiwan & Taiwan & 2.83 & 6 & 73.14 & 23 \\
\hline 26 & Peking University & China & 2.75 & 8 & 57.76 & 26 \\
\hline 27 & National Chengchi University & Taiwan & 2.58 & 8 & 56.09 & 27 \\
\hline 28 & Hong Kong Institute for Monetary Research & Hong Kong & 2.50 & 4 & 30.93 & 43 \\
\hline 29 & University of Western Australia & Australia & 2.33 & 4 & 51.27 & 31 \\
\hline 30 & Singapore Stock Exchange & Singapore & 2.17 & 4 & 47.20 & 33 \\
\hline 30 & University of Technology, Sydney & Australia & 2.17 & 4 & 44.58 & 35 \\
\hline 32 & Bond University & Australia & 2.00 & 3 & 51.90 & 29 \\
\hline 33 & Seoul National University & Korea & 2.00 & 6 & 65.16 & 25 \\
\hline 34 & Sungkyunkwan University & Korea & 1.92 & 5 & 40.13 & 37 \\
\hline 35 & Lingnan University & Hong Kong & 1.83 & 3 & 52.95 & 28 \\
\hline 36 & Tsinghua University & China & 1.67 & 4 & 32.06 & 40 \\
\hline 37 & Hanyang University & Korea & 1.58 & 4 & 49.51 & 32 \\
\hline 37 & University of Otago & New Zealand & 1.58 & 4 & 32.54 & 39 \\
\hline 39 & Korea Advanced Institute of Science and Technology & Korea & 1.50 & 3 & 45.93 & 34 \\
\hline 39 & Providence University, Taichung & Taiwan & 1.50 & 3 & 29.30 & 48 \\
\hline 39 & Keio University & Japan & 1.50 & 2 & 41.78 & 36 \\
\hline 39 & Nagoya University & Japan & 1.50 & 2 & 29.30 & 47 \\
\hline 39 & Renmin University & China & 1.50 & 2 & 24.96 & 60 \\
\hline 39 & Griffith University & Australia & 1.50 & 2 & 17.17 & 76 \\
\hline 45 & University of International Business and Economics & China & 1.50 & 4 & 29.81 & 45 \\
\hline 45 & National Cheng Kung University & Taiwan & 1.50 & 4 & 26.04 & 58 \\
\hline 47 & Hong Kong Baptist University & Hong Kong & 1.33 & 4 & 27.45 & 51 \\
\hline 47 & National Chiao Tung University & Taiwan & 1.33 & 2 & 31.50 & 41 \\
\hline 47 & University of Southern Queensland & Australia & 1.33 & 2 & 29.66 & 46 \\
\hline 47 & American University, Sharjah & Pakistan & 1.33 & 2 & 25.86 & 59 \\
\hline
\end{tabular}


The Australasian Accounting Business \& Finance Journal, September, 2008. Jarnecic, Segara, Segara, and Westerholm: Scholarly Output Academics Asia-Pacific Finance.

Vol. 2, No.3. Page 49.

\section{Appendix 1 (Cont'd)}

\begin{tabular}{|c|c|c|c|c|c|c|}
\hline Rank & Institution name & Country & $\begin{array}{l}\text { Weighted } \\
\text { articles }\end{array}$ & $\begin{array}{l}\text { Unweighted } \\
\text { articles }\end{array}$ & $\begin{array}{l}\text { Weighted } \\
\text { JF - Pages }\end{array}$ & $\begin{array}{c}\text { Rank based on } \\
\text { Weighted JF-Pages }\end{array}$ \\
\hline \multicolumn{7}{|c|}{ Panel C. The top 21 to 50 Asia-Pacific institutions ranked by total weighted count in the top 10 finance journals (Group 2) } \\
\hline 21 & Massey University & New Zealand & 2.00 & 5 & 46.93 & 22 \\
\hline 21 & Korea Advanced Institute of Science and Technology & Korea & 2.00 & 4 & 60.36 & 18 \\
\hline 21 & University of Western Australia & Australia & 2.00 & 3 & 40.42 & 26 \\
\hline 24 & Royal Melbourne Institute of Technology (RMIT) & Australia & 1.83 & 4 & 35.63 & 32 \\
\hline 24 & University of Technology, Sydney & Australia & 1.83 & 3 & 45.63 & 23 \\
\hline 26 & Seoul National University & Korea & 1.67 & 5 & 52.87 & 21 \\
\hline 26 & Tsinghua University & China & 1.67 & 4 & 35.22 & 33 \\
\hline 28 & Peking University & China & 1.58 & 4 & 42.75 & 25 \\
\hline 29 & University of Queensland & Australia & 1.50 & 4 & 36.91 & 31 \\
\hline 29 & National Kaohsiung First University of Science \& Tech & Taiwan & 1.50 & 2 & 28.76 & 38 \\
\hline 31 & Sungkyunkwan University & Korea & 1.50 & 4 & 38.74 & 28 \\
\hline 32 & Korea Development Institute & Korea & 1.33 & 3 & 44.01 & 24 \\
\hline 32 & Hitotsubashi University & Japan & 1.33 & 2 & 39.86 & 27 \\
\hline 32 & University of Tsukuba & Japan & 1.33 & 2 & 37.86 & 29 \\
\hline 35 & University of Otago & New Zealand & 1.25 & 3 & 25.67 & 42 \\
\hline 36 & Yonsei University & Korea & 1.08 & 3 & 36.96 & 30 \\
\hline 36 & Cheung Kong Graduate School of Business & China & 1.08 & 3 & 26.56 & 41 \\
\hline 38 & Hanyang University & Korea & 1.00 & 2 & 26.63 & 40 \\
\hline 38 & South Korean University & Korea & 1.00 & 2 & 6.90 & 99 \\
\hline 38 & Reserve Bank of Australia & Australia & 1.00 & 1 & 31.27 & 36 \\
\hline 38 & La Trobe University & Australia & 1.00 & 1 & 24.00 & 45 \\
\hline 38 & China Europe International Business School (CEIBS) & China & 1.00 & 1 & 19.68 & 46 \\
\hline 38 & Academia Sinica & Taiwan & 1.00 & 1 & 16.65 & 51 \\
\hline 38 & Korea Institute for International Economic Policy & Korea & 1.00 & 1 & 15.68 & 54 \\
\hline 38 & IBMEC & Singapore & 1.00 & 1 & 12.64 & 63 \\
\hline 38 & Nomura & Japan & 1.00 & 1 & 12.11 & 68 \\
\hline 47 & National Chengchi University & Taiwan & 0.92 & 3 & 24.08 & 43 \\
\hline 47 & National Chung Cheng University & Taiwan & 0.92 & 3 & 24.08 & 43 \\
\hline 49 & Indian Institute of Management & India & 0.83 & 2 & 32.58 & 35 \\
\hline 49 & Lingnan University & Hong Kong & 0.83 & 2 & 29.07 & 37 \\
\hline \multicolumn{7}{|c|}{ Panel D. The top 21 to 50 Asia-Pacific institutions ranked by total weighted count in the top 5 finance journals } \\
\hline 21 & Hitotsubashi University & Japan & 1.33 & 2 & 39.86 & 18 \\
\hline 22 & Sungkyunkwan University & Korea & 1.17 & 3 & 27.65 & 24 \\
\hline 23 & Cheung Kong Graduate School of Business & China & 1.08 & 3 & 26.56 & 27 \\
\hline 23 & Peking University & China & 1.08 & 3 & 24.87 & 30 \\
\hline 25 & Hanyang University & Korea & 1.00 & 2 & 26.63 & 26 \\
\hline 25 & Tsinghua University & China & 1.00 & 2 & 20.22 & 34 \\
\hline 25 & Reserve Bank of Australia & Australia & 1.00 & 1 & 31.27 & 22 \\
\hline 25 & University of Western Australia & Australia & 1.00 & 1 & 25.70 & 29 \\
\hline 25 & La Trobe University & Australia & 1.00 & 1 & 24.00 & 31 \\
\hline 25 & Korea Institute for International Economic Policy & Korea & 1.00 & 1 & 15.68 & 37 \\
\hline 25 & IBMEC & Singapore & 1.00 & 1 & 12.64 & 42 \\
\hline 25 & Kyoto University & Japan & 1.00 & 1 & 10.87 & 51 \\
\hline 25 & University of Sydney & Australia & 1.00 & 1 & 6.18 & 63 \\
\hline 34 & Kobe University & Japan & 0.83 & 2 & 27.97 & 23 \\
\hline 35 & University of Otago & New Zealand & 0.75 & 2 & 21.88 & 33 \\
\hline 35 & China Center for Financial Research & China & 0.75 & 2 & 8.92 & 59 \\
\hline 37 & Hankuk University & Korea & 0.67 & 2 & 27.19 & 25 \\
\hline 37 & Shanghai University of Finance and Economics & China & 0.67 & 2 & 15.21 & 38 \\
\hline 39 & Yonsei University & Korea & 0.58 & 2 & 22.57 & 32 \\
\hline 40 & International University of Japan & Japan & 0.50 & 2 & 9.39 & 57 \\
\hline 40 & Korea Advanced Institute of Science and Technology & Korea & 0.50 & 1 & 32.57 & 21 \\
\hline 40 & Fudan University & China & 0.50 & 1 & 18.78 & 35 \\
\hline 40 & The World Bank & Thailand & 0.50 & 1 & 18.28 & 36 \\
\hline 40 & Massey University & New Zealand & 0.50 & 1 & 13.84 & 39 \\
\hline 40 & Fu-Jen Catholic University & Taiwan & 0.50 & 1 & 13.50 & 40 \\
\hline 40 & Korea Development Institute & Korea & 0.50 & 1 & 13.32 & 41 \\
\hline 40 & Curtin University of Technology & Australia & 0.50 & 1 & 12.35 & 44 \\
\hline 40 & National Kaohsiung First University of Science \& Tech & Taiwan & 0.50 & 1 & 11.58 & 47 \\
\hline 40 & Ewha Women's University & Korea & 0.50 & 1 & 11.50 & 48 \\
\hline 40 & Indian School of Business & India & 0.50 & 1 & 11.00 & 50 \\
\hline
\end{tabular}

